\title{
An In Situ and Real Time Plasmonic Approach of Seed/Adhesion Layers: Chromium Buffer Effect at the Zinc/Alumina Interface
}

\author{
Maya Messaykeh, ${ }^{\dagger}$ Stéphane Chenot $^{\dagger}{ }^{\text {Pascal David }},^{\dagger}$ Gregory Cabailh $^{\dagger}{ }^{\dagger}$ Jacques \\ Jupille, ${ }^{\dagger}$ Alexey Koltsov, ${ }^{\ddagger}$ and Rémi Lazzari*, ${ }^{\dagger}$ \\ $\dagger C N R S$, Sorbonne Université, Institut des NanoSciences de Paris, UMR 7588, 4 Place \\ Jussieu, F-75005 Paris, France \\ $\ddagger$ ArcelorMittal Maizières Research, voie Romaine, F-57280, Maizières-lès-Metz, France \\ E-mail: remi.lazzari@insp.jussieu.fr
}

\section{Abstract}

The effect of additives on metal/oxide interfaces is explored in situ and in real time on evaporated films by a combination of surface science techniques, among which a very flexible optical method shows a unique ability to scrutinize the growth and wetting properties of supported clusters that involve several elements. The study focuses on $\mathrm{Cr}$ at the $\mathrm{Zn} / \alpha$ $\mathrm{Al}_{2} \mathrm{O}_{3}(0001)$ interface at $300 \mathrm{~K}$. A particular interest of the present interface is that $\mathrm{Zn}$ does not stick at all on bare alumina. The sticking and morphology of both $\mathrm{Cr}$ and $\mathrm{Zn}$ films are analyzed from submonolayer to multilayer thicknesses, during their growth. After an initial oxidation reaction with residual $\mathrm{OH}$ groups, shown to be detrimental to $\mathrm{Zn}$ adhesion, Cr growth proceeds through the formation of high aspect ratio particles that percolate around an average thickness of $10 \AA$. As regards to Zn growth on a Cr deposit, two very distinct stages can be distinguished. In the submonolayer thickness range, Cr forms a seed layer that drastically increases the $\mathrm{Zn}$ sticking coefficient from zero to nearly one due to a diffusion length of physisorbed $\mathrm{Zn}$ adatoms before desorption larger than $\mathrm{Cr}$ island separation; Zn clusters are anchored on the $\mathrm{Cr}$ seeds that they encapsulate, but their wetting behavior is dictated by the interaction with alumina. In a second stage, as soon as the Cr film percolates, it forms an adhesion layer on which $\mathrm{Zn}$ grows in a nearly 2D mode. In all cases, $\mathrm{Cr}$ films are stable upon annealing. On Cr-covered alumina, the Zn desorption energy is enhanced as compared to bare surfaces which, in line with atomistic simulations, is assigned to the formation of more favorable $\mathrm{Cr}-\mathrm{Al}_{2} \mathrm{O}_{3}$ and $\mathrm{Cr}-\mathrm{Zn}$ than $\mathrm{Zn}-\mathrm{Al}_{2} \mathrm{O}_{3}$ bonds. Generally speaking, the ability demonstrated herein of small amounts of additives to dramatically increase the adhesion of films is of great practical interest. It shows that non-continuous and partially oxidized films of additives, closer to realistic cases of application, can strongly enhance the sticking of films. Also, anchoring a functional film by discrete pre-deposited seeds can keep its properties intact.

\section{Introduction}

Oxide-supported continuous metallic films are involved in countless fields. ${ }^{1}$ A constant obstacle to their applications is the poor wetting of dielectric substrates by metals ${ }^{2,3}$ which leads to $3 \mathrm{D}$ growth morphology, in particular in the case of late transition or coinage metals $(\mathrm{Cu}$, $\mathrm{Zn}, \mathrm{Ag}, \mathrm{Pt}, \mathrm{Au}$ ) when these are often the most relevant choices for their specific properties. Kinetics can compensate for thermodynam- 
ics and allows percolation by acting on the atom diffusion lengths via the substrate temperature, the flux of impinging species or even their kinetic energy. Yet synthesized films are inherently out-of-equilibrium and prone to mechanical failure due to stress, ${ }^{4,5}$ aging or dewetting $^{6-8}$ that are detrimental to the continuous film properties. Therefore, obtaining reliable assemblies requires more sophisticated engineering solutions, such as the pre-deposited intermediate layers used to stabilize transparent conductive films, metamaterials or plasmonics devices which need flat and sharp interfaces as well as optimized thickness ${ }^{9}$ and roughness. ${ }^{10,11,11-15}$ Those layers are called alternatively seed ${ }^{10,12,13,16}$ or nucleation ${ }^{14}$ layers, adhesion ${ }^{17-19}$ or wetting ${ }^{11}$ layers, surfactants, ${ }^{9,20}$ or buffers. ${ }^{21,22}$ The term "buffer" will be used in what follows, because of its generality, before more precise indications emerge from the discussion. Buffers commonly involve transition metals $\left(\mathrm{Ni} ;{ }^{23} \mathrm{Cr}, \mathrm{Ti} ;{ }^{9,16-19,22,24} \mathrm{Nb} ;{ }^{10} \mathrm{Ta} ;{ }^{16}\right.$ $\left.\mathrm{Zr} ;{ }^{16} \mathrm{~W}^{16}\right), \mathrm{Sn},{ }^{20} \mathrm{Cu},{ }^{13} \mathrm{Ge}^{11,12,14}$ or even some specific oxides. ${ }^{17,18}$

From a thermodynamic adhesion point of view, buffers replace the weak metal/substrate bonds by stronger metal/metal and metal/substrate bonds that basically scale with the heat of formation of the parent metal oxides. ${ }^{25-27}$ But, according to the Bauer criterion, ${ }^{28}$ this favorable effect is balanced by the intrinsic non-wetting behavior of transition metals used in buffers on oxides such as alumina and silica. ${ }^{29,30}$ However in practice, from a growth point of view, they spread quite well because of a reduced surface mobility as often pointed by their low homologous (growth/melting) temperatures. ${ }^{28,31,32}$ Images recorded ex situ by atomic force microscopy (AFM) in Figure 1 illustrate the point. Silver deposited on alumina at $300 \mathrm{~K}$ forms $3 \mathrm{D}$ aggregates (Figure 1-a) close to equilibrium since the found contact angle $\left(127^{\circ}\right)^{22,33,34}$ is equal to that measured by the sessile drop method $\left(127-131^{\circ}\right) .{ }^{25,29}$ In the case of titanium, the "contact angle" determined at $300 \mathrm{~K}$ $\left(\sim 30^{\circ}\right),{ }^{22,35}$ although much smaller than the equilibrium value $\left(78^{\circ}\right),{ }^{25,29}$ clearly shows that the metal does not perfectly wet the oxide.
However, because the apparent growth mode is largely based on kinetics, Ti quickly covers the surface unlike Ag (Figure 1-b versus 1-a). Similar AFM images are observed for $\mathrm{Al} /{ }^{22}$ and Co/alumina, ${ }^{36}$ although these metals do not wet this oxide from a thermodynamic point of view. ${ }^{29}$ Generally speaking, the highly electropositive metals used in buffers to enhance the adhesion of late transition and coinage metals do no wet large band gap oxides such as alumina and silica. ${ }^{29,30}$ These contrasting behaviors are central in buffer effects.

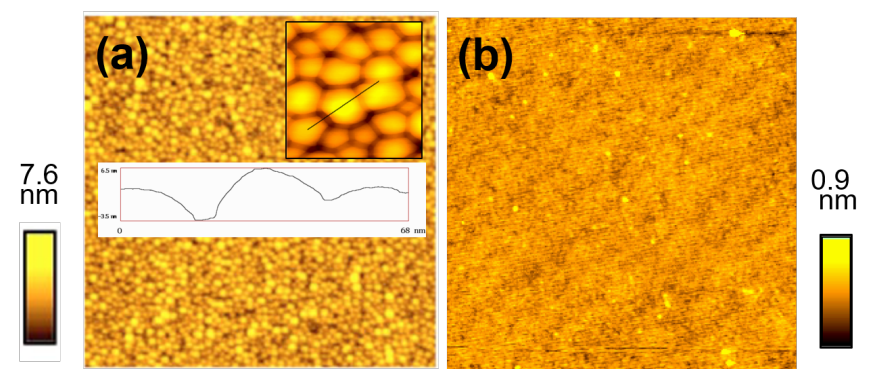

Figure 1: Atomic force microscopy images $(1 \times$ 1) $\mu \mathrm{m}^{2}$ recorded ex situ of metal $/ \alpha-\mathrm{Al}_{2} \mathrm{O}_{3}(0001)$ films deposited in ultra-high vacuum at $300 \mathrm{~K}$ : (a) $3 \mathrm{~nm} \mathrm{Ag} \mathrm{(from} \mathrm{Reference} \mathrm{22);} \mathrm{the} \mathrm{in-}$ set shows a $(100 \times 100) \mathrm{nm}$ zoom with the height profile corresponding to the black line; (b) $1.4 \mathrm{~nm} \mathrm{Ti}$; the steps of the alumina surface are visible with heights corresponding to interatomic distances (from Reference 35).

Most studies focus on final effects of rather thick ( $>1 \mathrm{~nm}$ ) buffer layers but neglect in situ observation of the growth and interfacial chemistry despite the importance of the morphology of buffers on how they operate. For example, the reduction in thickness of buffers is frequently sought to minimize their impact on the properties of coatings, ${ }^{9,10,12,18,20}$ although the behavior of these additives in the submonolayer range can be suspected to differ greatly from that of thicker layers, whose effects, far from uniform, ${ }^{16}$ can even become detrimental. ${ }^{16,21}$ The present work aims to monitor in situ and in real time, by surface differential reflectivity spectroscopy, the mechanisms involved from the very first stages of the growth of $\mathrm{Zn}$ on Cr-precovered alumina surfaces. The case is 
relevant to the development of advanced highstrength steels (AHSS) used by the automotive industry to lighten car weight to comply with energy saving rules. To improve mechanical properties, AHSS grades involve electropositive elements such as $\mathrm{Al}$ whose drawback is the oxygen-induced segregation at steel surfaces. ${ }^{37-39}$ The resulting surface oxide then degrades the adhesion of the anti-corrosive $\mathrm{Zn}$ coating during the galvanization process. ${ }^{40,41}$ The issue has motivated a series of studies ${ }^{42-47}$ on the model $\mathrm{Zn} / \alpha-\mathrm{Al}_{2} \mathrm{O}_{3}(0001)$ interface. First-principle simulations ${ }^{43,44,46}$ have shown the effectiveness of $\mathrm{Cr}>\mathrm{Fe}>\mathrm{Ni}$ in promoting strong metal-oxygen and metal-zinc bonds and shifting cleavage from interfacial to cohesive. In a surface science perspective, the effect of the $\mathrm{Cr}$ additive on the $\mathrm{Zn} / \mathrm{Cr} / \alpha-\mathrm{Al}_{2} \mathrm{O}_{3}(0001)$ adhesion offers a unique test bed since, under ultra-high vacuum (UHV), Zn does not stick at all on bare alumina above $220 \mathrm{~K} .{ }^{45,48,49}$ Moreover, the $\alpha-\mathrm{Al}_{2} \mathrm{O}_{3}(0001)$ surface is a popular support ${ }^{10,21,22,24,26}$ and $\mathrm{Cr}$ is a common additive ${ }^{9,16-18}$ which is theoretically predicted to be highly efficient at the $\mathrm{Zn} / \alpha-\mathrm{Al}_{2} \mathrm{O}_{3}(0001)$ interface. ${ }^{46}$

The used differential reflectivity technique has proven its ability to analyze growing films of $\mathrm{Ag},{ }^{22,33,34} \mathrm{Al},{ }^{22} \mathrm{Ti}^{22}$ and $\mathrm{Zn}^{45}$ at coverages of a tenth of a monolayer or less. The direct determination of the aspect ratio of supported particles allows an unique approach of their wetting. ${ }^{22,33,34,45,50}$ The interplay between the pre-deposited $\mathrm{Cr}$ buffer and the sticking and adhesion of the $\mathrm{Zn}$ overlayer is explored herein by an in situ approach performed in UHV conditions from the very early stages of the film growth. In addition, the study implements photoemission spectroscopy to determine chemical state and thickness but also temperature programmed desorption to probe $\mathrm{Zn}$ bonding. The question at hand is the role of Cr film thickness, chemical state and morphology in the improvement of Zn sticking and adhesion.

\section{$2 \quad$ Experimental details}

Experiments have been performed in a UHV vessel composed of a preparation (base pressure $2.10^{-10}$ mbar) and an analysis chamber (5. $10^{-11}$ mbar) equipped with X-ray Photoelectron Spectroscopy (XPS), Low Energy Electron Diffraction (LEED), Temperature Programmed Desorption (TPD) and Surface Differential Reflectivity Spectroscopy (SDRS). Epipolished $(9 \times 9 \times 0.5) \mathrm{mm}^{3} \alpha-\mathrm{Al}_{2} \mathrm{O}_{3}(0001)$ single crystals (supplier MaTecK ${ }^{51}$ ) were annealed at $\sim 1200 \mathrm{~K}$ by electron bombardment of the sample backplate under pure grade oxygen; gas was provided by a carefully out-gased doser, made of a bundle of metallic tubes, placed a millimeter from the surface to increase the local partial pressure by more than an order of magnitude compared to the chamber pressure $\left(p \simeq 2.10^{-6}\right.$ mbar $) .{ }^{52}$ A sharp $(1 \times 1)$ LEED pattern was then obtained. Alrich reconstructed surfaces $\left[(\sqrt{3} \times \sqrt{3}) \mathrm{R} 30^{\circ}\right.$, $(3 \sqrt{3} \times 3 \sqrt{3}) \mathrm{R}^{\circ} 0^{\circ}$ or $(\sqrt{31} \times \sqrt{31}) \mathrm{R} \pm 9^{\circ} \mathrm{ob}-$ tained by high temperature annealing in vacuum $^{53-55}$ have served as models of dry (or $\mathrm{OH}$ free) surface in TPD. ${ }^{45}$ Contaminants, in particular carbon, were below the detection limit of XPS, except for calcium that segregated up to an apparent thickness of $1 \AA$ on reconstructed surfaces. It does not impact LEED nor X-ray ${ }^{53-55}$ patterns, i.e. the surface crystallography. Previous transmission electron microscopy ${ }^{56}$ pointed to a Ca spread over four subsurface cation planes. Because of these observations and since Ca, absent from the environment of $\mathrm{Cr}$ probed by Extended X-ray Absorption Fine Structure, ${ }^{47}$ does not show XPS change upon $\mathrm{Cr}$ deposition, it has been assumed not to affect the following conclusions.

Cr was evaporated from a metallic rod heated by electron bombardment (Omicron EFM3) and $\mathrm{Zn}$ from an effusion cell (MBE Komponenten) held at $643 \mathrm{~K}$. Both sources were calibrated by a quartz microbalance set at the sample location (evaporation rate $\sim 1 \AA \cdot \mathrm{min}^{-1}$ ). However, thicknesses used herein refer only to photoemission determination (see below). Depositions were performed at $300 \mathrm{~K}$ at a base 
pressure $p<1.10^{-9}$ mbar. Although no significant metallic $\mathrm{Cr}$ aging was observed over the time scale of measurements, no cumulative deposition was performed. A new substrate was used for each $\mathrm{Cr}$ deposit. Cr oxide layers were obtained by prolonged oxidation at $T \sim 1575 \mathrm{~K}$ of Cr films under gas doser $\left(p=2.10^{-6} \mathrm{mbar}\right)$; thicknesses were determined by photoemission assuming a $\mathrm{Cr}_{2} \mathrm{O}_{3}$ structure. $\mathrm{Cr}$ and $\mathrm{Zn}$ growths were followed in real time by SDRS in the ultra-violet/visible photon range (1.5-5.5 eV) both in $\mathrm{p}$ - and s-polarizations. ${ }^{57}$ Spectra were systematically normalized to the bare alumina reflectivity. The reflection coefficients of the films were expressed using interfacial susceptibilities that have the meaning of "dielectric thicknesses" which combine geometry and dielectric properties (see References 58,59 for definitions). By polarizing metal particles, the electric field of the incident light (incidence of $\theta_{0}=45^{\circ}$ ) excites plasmon resonances which are sensitive to morphology even for transition metals, despite broadening. ${ }^{50,57}$ To derive particle shape from optics, islands were modeled by truncated spheroids ${ }^{35}$ to fit recorded spectra in the framework of a dielectric formalism $^{22,33,57,60}$ (Section SII of supporting information). These are in line with previous dielectric simulations ${ }^{57,61-65}$ which turned out to be efficient in unraveling growth modes and change in wetting $22,33,50,60$ at metal/dielectric interfaces. For both $\mathrm{Cr}$ and $\mathrm{Zn}$ films, only s-polarization has been considered since, beyond a scaling in intensity due to substrate reflectivity, the response for the two polarizations hardly differs for flat particles (Figures S1-b,c, S2, S3 and S4).

Chemical states and thicknesses were examined by XPS at normal emission under nonmonochromatic excitation with a hemispherical analyzer (Phoibos 100 from SPECS; delay line detector) at a pass energy of either $20 \mathrm{eV}$ or $50 \mathrm{eV}$. Al-K $\alpha$ and $\mathrm{Mg}-\mathrm{K} \alpha$ excitations were used alternatively for $\mathrm{Cr}$ and $\mathrm{Cr}+\mathrm{Zn}$ deposits to avoid overlap between core levels and Auger transitions. No charge compensation was applied. Ratios of substrate (O $1 \mathrm{~s}$ and $\mathrm{Al} 2 \mathrm{~s}$ ) and deposit ( Cr 2p and Zn 2p) core-level areas were used to estimate thicknesses after correc- tion from analyzer transmission function and photoionization cross sections ${ }^{66}$ (Table S1). Areas were obtained after subtraction of a Tougaard universal background ${ }^{67}$ with parameters $B=3006 \mathrm{eV}^{2}$ and $C=1643 \mathrm{eV}^{2}$. Care was taken to subtract the second plasmon satellite of $\mathrm{O}$ 1s under the $\mathrm{Cr} 2 \mathrm{p}$ core level to quantify thin Cr films. Despite partial coverage, a model of signal damping through a stack of continuous films ${ }^{68}$ was used with effective attenuation lengths (Table S2) obtained by combining elastic transport theory ${ }^{69-71}$ and TPP2M predictive formula $^{72}$ for inelastic mean free paths as implemented in the $I_{4} P$ package. ${ }^{73}$ Bulk densities and stoichiometries of $\mathrm{Cr}, \mathrm{Zn}$ and $\mathrm{Cr}_{2} \mathrm{O}_{3}$ were used to define film thicknesses.

Zn desorption (mass/charge of $m / e=64$ ) was followed by TPD from 300 to $700 \mathrm{~K}$ at a heating rate of $0.33 \mathrm{~K} . \mathrm{s}^{-1}$. The mass spectrometer (MS, PrismaPlus QMG220) was enclosed in a quartz tube the aperture of which was brought in the vicinity of the substrate (in such way that the sample is in line of sight of the MS) to only probe $\mathrm{Zn}$ desorption. ${ }^{45}$ Desorption energy and order were obtained from the Polanyi-Wigner equation ${ }^{74}$ using the Redhead formula ${ }^{75}$ or the leading edge analysis ${ }^{76}$ (see supplemental material of Reference 45 and Section SIII).

\section{Results and discussion}

To explore the impact of $\mathrm{Cr}$ buffers on the sticking and adhesion of Zn, alumina substrates precovered by increasing amounts of Cr were exposed to a given $\mathrm{Zn}$ dose of $\sim$ $15 \AA$. Similar deposits were also performed on purposely oxidized $\mathrm{Cr}$ films. The growth of $\mathrm{Cr} / \alpha-\mathrm{Al}_{2} \mathrm{O}_{3}(0001)$, the sticking, desorption and growth of $\mathrm{Zn}$ deposited on $\mathrm{Cr} / \alpha-\mathrm{Al}_{2} \mathrm{O}_{3}(0001)$ are successively presented.

\subsection{Chromium growth mode on $\alpha-\mathrm{Al}_{2} \mathrm{O}_{3}(0001)$ from optics}

The growth of $\mathrm{Cr} / \mathrm{Al}_{2} \mathrm{O}_{3}(0001)$ was monitored by SDRS (Figure 2-a,b). The similarity between the dielectric constants of Cr (Figure S1- 

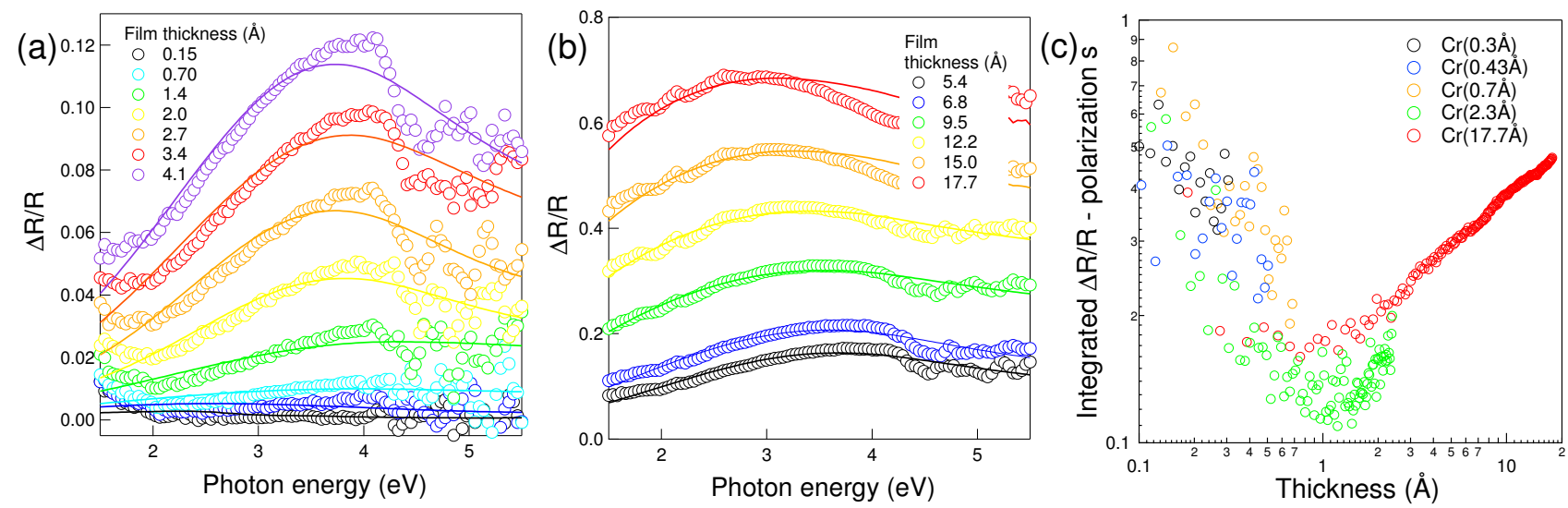

Figure 2: Differential reflectivity during growth of $\mathrm{Cr} / \mathrm{Al}_{2} \mathrm{O}_{3}(0001)$ : (a)(b) fits (lines) with a dielectric model of the s-polarization spectra (points). Film thicknesses are scaled on evaporation time from the obtained photoemission calibration at the end of the deposition process. The higher noise in the ultraviolet range is due to a lower absolute reference signal. (c) Evolution with thickness of the integrated SDRS s-polarized signal $\mathcal{A}_{s}$ normalized to thickness (Equation 1) for different $\mathrm{Cr}$ deposits. Integration is performed over the accessible photon energy range.
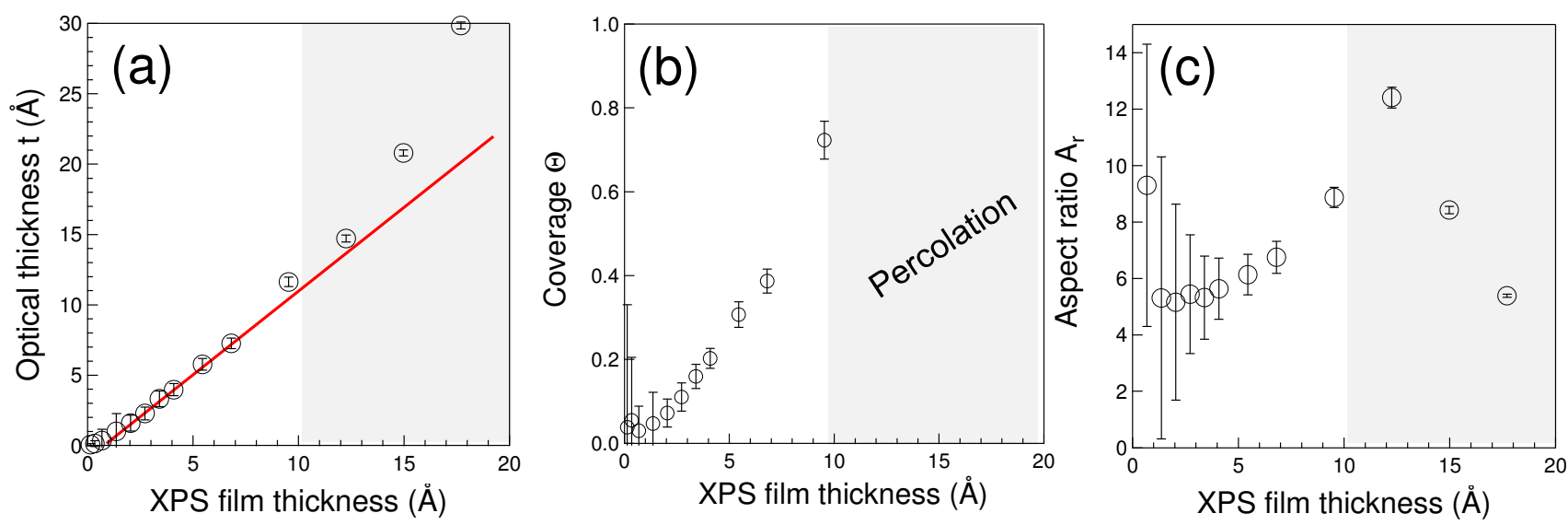

Figure 3: Morphology of $\mathrm{Cr} / \mathrm{Al}_{2} \mathrm{O}_{3}(0001)$ from SDRS fits: (a) optical thickness $t$, (b) surface coverage $\Theta$ and (c) particle aspect ratio $A_{r}$ versus deposited thickness. Shaded regions correspond to the breakdown of the model with hemispheroids, which is associated to the percolation within the Cr film. 
a) and $\mathrm{Zn}$ (Figure S4-a) combined with previous findings on plasmonics of $\mathrm{Zn} / \mathrm{Al}_{2} \mathrm{O}_{3}{ }^{59}$ shows that the observed broad resonance for Cr corresponds to the excitation in particles of a parallel dipole polarization mode on the tail of interband transitions. ${ }^{77}$ The evolution of the particle aspect ratio $\left(A_{r}=\right.$ parallel diameter/height) and therefore wetting can be gained through the integrated SDRS signal in s-polarization, normalized to film thickness $t,{ }^{50}$ defined by:

$$
\mathcal{A}_{s}(t)=\frac{c}{4 \cos \theta_{0} t\left(\epsilon_{S}-1\right)} \int_{0}^{\infty} \frac{\Delta R_{s}}{R_{s}}(\omega, t) \frac{d \omega}{\omega}
$$

where $\epsilon_{S}$ is the dielectric function of alumina ( $\epsilon_{S} \simeq 3$ in ultra-violet/visible), $\theta_{0}$ the incident angle and $c$ the speed of light. Mainly driven by the oscillator strength of the parallel plasmon resonance, $\mathcal{A}_{s}(t)$ directly accounts for $A_{r} \cdot{ }^{50} \mathrm{Its}$ reproducible U-shaped evolution (Figure 2-c) points to a $3 \mathrm{D}$ growth mode with (i) an initial stress-driven flattening $(t<1 \AA$ ), (ii) a growth at constant $A_{r}$ around $t \simeq 1 \AA$ and (iii) a coalescence/coarsening $(t>2 \AA)^{50}$ that occurs herein much earlier in thickness than for less adhesive noble metals. ${ }^{22,33,50}$ In a more quantitative analysis, SDRS profiles have been fitted (Figure 2-a,b) in the framework of the GranFilm $^{62,65}$ package using tabulated dielectric constants ${ }^{78}$ and extra-broadening of about $1 \mathrm{eV}$ to account for polydispersity ${ }^{33,64}$ (see Section SII). The evolutions of film thickness, surface coverage and $A_{r}$ are reported in Figure 3 as a function of the $\mathrm{Cr}$ thickness determined by XPS. The one-to-one correlation (Figure 3-a, slope 0.9) between SDRS and XPS thicknesses validates the approach. The absence of plasmonic response at the onset of $\mathrm{Cr}$ deposition, up to $\sim 0.5 \AA$ (Figure $3-\mathrm{a}$ ), is attributed to oxidation by reaction with surface $\mathrm{OH} ;{ }^{47}$ the formation of defined $\mathrm{Cr}^{3+}{ }_{-} \mathrm{O}_{2} \mathrm{H}$ moities was evidenced by X-ray absorption combined to $a b$ initio calculations, ${ }^{47}$ while photoemission revealed that $\mathrm{Cr}$ is oxidized but does not reduce alumina. ${ }^{47,77}$ Similar reactions are observed at various metal/oxide interfaces ${ }^{79}$ and, more specifically, for $\mathrm{Rh},{ }^{80} \mathrm{Cu},{ }^{81,82} \mathrm{Co},{ }^{36} \mathrm{Zn},{ }^{45} \mathrm{Ti}$ and $\mathrm{Al}^{22,83}$ on $\alpha-\mathrm{Al}_{2} \mathrm{O}_{3}(0001)$.
As regards to the aspect ratio $A_{r}$, the evolution from high values at the onset of the growth to a minimum around 1-2 $\AA$, and a final regular increase (Figure 3-c) parallel the U-shaped curve of $\mathcal{A}_{s}(t)$ (Figure 2-c). At a $\mathrm{Cr}$ thickness of $10 \AA$, the analysis based on the quasi-static approximation becomes inconsistent (shaded regions in Figure 3), likely because the film percolates as also suggested by the disappearance of charge effects in photoemission. From a truncated sphere model of the $\mathrm{Cr}$ cluster, a wetting angle $\theta_{e}\left(\mathrm{Cr} \mid \mathrm{Al}_{2} \mathrm{O}_{3}\right)=37^{\circ}$ is obtained from the minimum value $A_{r}=5$ (Figure $3-\mathrm{c}$ ). This value is much smaller than that $\theta_{e}\left(\mathrm{Cr} \mid \mathrm{Al}_{2} \mathrm{O}_{3}\right)=109^{\circ}$ derived from the calculated adhesion energy $W\left(\mathrm{Cr} \mid \mathrm{Al}_{2} \mathrm{O}_{3}\right)=1.85 \mathrm{~J} / \mathrm{m}^{2}$ (average of References 45,84$)$ by applying the Young-Dupré equation $W\left(\mathrm{Cr} \mid \mathrm{Al}_{2} \mathrm{O}_{3}\right)=\gamma(\mathrm{Cr})\left(1+\cos \theta_{e}\right)$ with a $\mathrm{Cr}$ surface energy $\gamma(\mathrm{Cr})=2.75 \mathrm{~J} / \mathrm{m}^{2}$ (average of References 45,84). The difference is however explained by the Markow and Kaischew's idea ${ }^{31}$ that the Bauer criterion of $2 \mathrm{D}$ growth ${ }^{28}$ has to be modified ${ }^{31}$ by including the free enthalpy released during condensation $\Delta \mu$ which, applied to $\mathrm{Cr}$, gives:

$$
\gamma\left(\mathrm{Al}_{2} \mathrm{O}_{3}\right)>\gamma(\mathrm{Cr})+\gamma\left(\mathrm{Cr} \mid \mathrm{Al}_{2} \mathrm{O}_{3}\right)-\frac{\Delta \mu}{A}
$$

or

$$
\cos \theta_{e}>1-\frac{\Delta \mu}{A \gamma(\mathrm{Cr})}
$$

where $A$ is the contact area of a metal atom at the interface. $\Delta \mu=k T_{s} \ln (\eta)$ scales with the supersaturation factor $\eta=p\left(T_{e f}\right) / p\left(T_{s}\right)$ where $p\left(T_{e f}\right)\left(p\left(T_{s}\right)\right)$ is the Cr vapor pressure at the effusion (substrate) temperature. Despite strong uncertainties in the extrapolation of the $\mathrm{Cr}$ vapor pressure $^{85}$ at low temperature $(\eta \approx 50)$, the inequality is easily fulfilled. Combined with the low diffusivity (low homologous temperature $\left.T_{h}(\mathrm{Cr})=0.14^{86,87}\right)$, this supersaturation effect explains the spreading of growing $\mathrm{Cr}$ particles and the two following points which, apparently contradictory, are in fact complementary: (i) Cr does not wet alumina as evidenced by SDRS (Figure 3-c) in agreement with thermodynamics $28,31,32$ and numerical simulations $;{ }^{45,84}$ (ii) the percolation observed at a $\mathrm{Cr}$ thickness of about $10 \AA$ (Figure 3 ) corresponds to an out-of- 
equilibrium behavior similar to that observed for $\mathrm{Ti} /, \mathrm{Al} /{ }^{22,35}$ and $\mathrm{Co} /$ alumina $^{36}$ as mentioned in the introductory section.

\subsection{Zinc sticking coefficient and chemical state}

The fraction of the $\sim 15 \AA$ evaporated dose of $\mathrm{Zn}$ which sticks on $\mathrm{Cr} / \alpha-\mathrm{Al}_{2} \mathrm{O}_{3}(0001)$ was quantified by photoemission using a continuous film model (Figure 4) although, at the onset of growth, this only indicates trends for $\mathrm{Zn}$ growing in the form of 3D particles. At $\mathrm{Cr}$ film thicknesses of less than $0.3 \AA$, the absence of sticking of $\mathrm{Zn}$ (Figure 4) is assigned to the oxidation of $\mathrm{Cr}$ at the onset of the growth ${ }^{47}$ since $\mathrm{Zn}$ hardly condenses on purposely oxidized Cr films (green triangle in Figure 4). The observation is supported by ab initio calculations of separation energies at the $\mathrm{Zn} / \mathrm{M}$ and $\mathrm{Zn} / \mathrm{MO}_{x}$ interfaces ( $\mathrm{M}$ for metal and $\mathrm{MO}_{x}$ for oxide) ${ }^{44}$ which showed that oxidation lowers the number of favorable metal/buffer bonds. As a rule of thumb, the reduction of the metallic $\mathrm{Cr}$ contribution, due to its oxidation, to $\mathrm{Zn}$ adhesion must be systematically accounted for. At higher Cr film thickness, the condensed fraction of Zn increases steeply up to $\sim 80 \%$ for a Cr coverage of $0.7 \AA$ and then more slowly. In stark contrast to the bare surface on which Zn does not bind at all at $300 \mathrm{~K},{ }^{45,48,49}$ minute fractions of $\mathrm{Cr}$ monolayer entail an almost complete sticking of the impinging zinc, which reveals zones of $\mathrm{Cr}$ influence which greatly exceed the actual covered surface (Figure 4). As the Cr film percolates above $\sim 10 \AA$ (Section 3.1), Zn entirely sticks on the surface. In what follows, Section 3.4 is devoted to the influence of Cr pre-deposition on $\mathrm{Zn}$ growth mode.

The known improvement in $\mathrm{Zn} /$ alumina adhesion by an activated reaction with surface $\mathrm{OH}^{42,45}$ suggests analyzing the chemical state of $\mathrm{Zn}$ which, because of the marginal chemical shift between $\mathrm{Zn}^{0}$ and $\mathrm{Zn}^{2+}\left(0.1 \mathrm{eV}\right.$ on $\left.\mathrm{Zn} 2 \mathrm{p}^{88}\right)$, is commonly examined in XPS ${ }^{45}$ via Auger line shapes and parameter $\alpha_{\mathrm{Zn}}=E_{B}\left(\mathrm{Zn} 2 \mathrm{p}_{3 / 2}\right)+$ $E_{K}\left(\mathrm{ZnL}_{3} \mathrm{M}_{45} \mathrm{M}_{45}\right)$. Herein, the observed $\mathrm{Zn}$
$\mathrm{L}_{3} \mathrm{M}_{45} \mathrm{M}_{45}$ Auger profile ${ }^{45,89-94}$ (not shown) and the value $\alpha_{\mathrm{Zn}}=2013.8 \pm 0.3 \mathrm{eV}$ (to be compared to tabulated ${ }^{88} 2013.9 \pm 0.25 \mathrm{eV}$ for metallic $\mathrm{Zn}$ and $2010.15 \pm 0.4 \mathrm{eV}$ for $\mathrm{ZnO}$ ) unambiguously demonstrate that $\mathrm{Zn}$ is metallic at all stages. Therefore, the dramatic improvement of the sticking of $\mathrm{Zn}$ on alumina (Figure 4) by a tiny amount of Cr only relies on the presence of metallic $\mathrm{Cr}$.

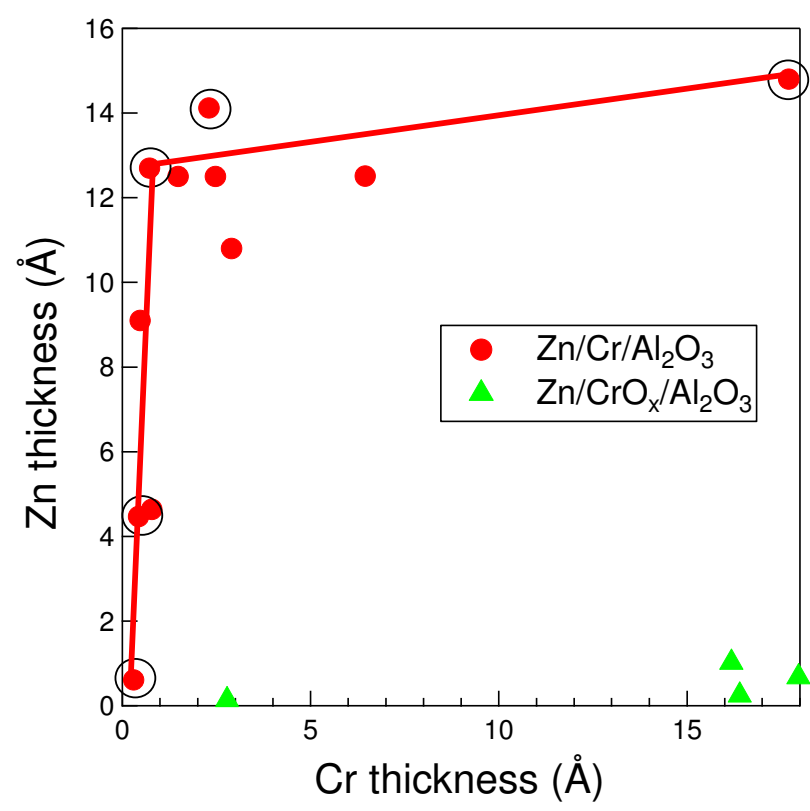

Figure 4: Correlation between the $\mathrm{Zn}$ condensed amount after an exposure to a constant nominal thickness of Zn (15 $\AA$ ) and the Cr predeposited thickness, either metallic (red circles) or oxidized (green triangle). All experiments are performed at $300 \mathrm{~K}$. Oxidized $\mathrm{Cr}$ thickness is defined for a $\mathrm{Cr}_{2} \mathrm{O}_{3}$ composition. Circled points correspond to films studied by SDRS.

\subsection{Chromium-induced enhance- ment of the zinc desorption energy}

Zn films deposited on Cr-precovered $\mathrm{Al}_{2} \mathrm{O}_{3}(0001)$ have been desorbed between 300 and $700 \mathrm{~K}$, reconstructed aluminas being models for dry surfaces in parallel to the partially hydroxylated $^{47}(1 \times 1)$ alumina (Figure 5 -a). Since $\mathrm{Zn}$ sticking changes with $\mathrm{Cr}$ thickness (Figure 4), the exposure time to $\mathrm{Zn}$ vapor was adapted 
to reach a condensed amount of $\mathrm{Zn}$ of about two monolayers to focus on the impact of the $\mathrm{Zn} / \mathrm{Cr}$ interface and to limit "bulk" Zn signal. On the two thick Cr films purposely oxidized prior to an exposure to a $\mathrm{Zn}$ nominal thickness of $\sim 45 \AA$, the tiny amount of desorbed $\mathrm{Zn}$ confirms the low Zn sticking on this surface at $300 \mathrm{~K}(\sim 0.5 \AA$; Figure 4$)$. The oxidized Cr films (green lines in Figure 5) give rise to two desorption peaks but, owing to the small amount of adsorbed $\mathrm{Zn}$, the analysis was restricted to the most intense feature. On the $(1 \times 1)$ surface, the $\mathrm{Zn}$ desorption peak shifts from 470 to $570 \mathrm{~K}$, broadens and gets asymmetric upon increasing $\mathrm{Cr}$ thickness (Figure 5a). On thick $\mathrm{Cr}$ films, the multicomponent desorption lines (red curves in Figure 5) suggest an alloying effect involving $\mathrm{Zn}$-rich $\mathrm{Zn}_{x} \mathrm{Cr}_{y}$ compounds found in the bulk phase diagram below $700 \mathrm{~K}$. In the same way, high desorption temperatures of $\mathrm{Zn}$ on $\mathrm{Ag}, \mathrm{Cu}, \mathrm{Ni}, \mathrm{Rh}, \mathrm{Rh}$, $\mathrm{Pt}, \mathrm{Pd}^{95-99}$ were attributed to alloying with supports. Finally, the overlap at a given $\mathrm{Cr}$ thickness of desorption signals normalized in intensity and position for both $(1 \times 1)$ and reconstructed surfaces demonstrates a similar $\mathrm{Zn}$ bonding dominated by metallic $\mathrm{Cr}$ (Figure 5-b).

Any $\mathrm{O}_{2}$ desorption is excluded since double ionization $\left(\mathrm{Zn}^{2+} ; m / e=32\right)$ leads to the same line shape as $\mathrm{Zn}^{+}$. No noticeable $\mathrm{ZnO}$ $(\mathrm{m} / \mathrm{e}=80)$ signal was observed. $\mathrm{Zn}$ is completely eliminated upon desorption, as demonstrated by the XPS analysis of $\mathrm{Zn} 2 \mathrm{p}$ whose high photoionization cross section guarantees a high sensitivity (Table S1). This contrasts with the desorption of $\mathrm{Zn}$ adsorbed at $100 \mathrm{~K}$ on the partially hydroxylated $(1 \times 1)$ alumina, where a fraction of $\mathrm{Zn}$ oxidizes by reaction with surface OHs and binds very strongly to the surface (desorption at $\simeq 1300 \mathrm{~K}) .{ }^{45}$ In the present case, $\mathrm{Zn}$ adsorbed on Cr-precovered alumina remains fully metallic and completely desorbs below $600 \mathrm{~K}$. The lack of $\mathrm{Cr}$ desorption signal $(m / e=52)$ and the constant $\mathrm{Cr}$ amount and XPS Cr 2p line shape before and after desorption (not shown) rules out any substantial reaction with the substrate ${ }^{100}$ and confirms the thermal stability of $\mathrm{Cr}$ expected from its low vapor pressure $\left(p_{C r} \ll 10^{-11}\right.$ mbar at $700 \mathrm{~K}$ as compared to $\left.p_{Z n} \simeq 10^{-1} \mathrm{mbar}\right)$.

Desorption activation energies $E_{a}$ determined by leading-edge analysis are compared to results obtained after $\mathrm{Zn}$ condensation on bare $(1 \times 1)$ and reconstructed surfaces at $100 \mathrm{~K}^{45,49}$ (Figure 6). An example of TPD analysis ${ }^{a}$ is given in Figure S6. In a broken bond model, estimates of $E_{a}$ are $9 / 12 E_{c o h}(\mathrm{Zn})$ for a $\mathrm{Zn}$ atom on a (0001) plane, $7 / 12 E_{\text {coh }}(\mathrm{Zn})$ on the [10 $\left.\overline{10}\right]$ step on a (0001) surface and $4 / 12 E_{\text {coh }}(\mathrm{Zn})$ for a kink atom since the coordination number of 12 for the hexagonal compact $\mathrm{Zn}$ reduces to 9, 7 and 4 for surface, step and kink, respectively. On dry reconstructed bare surfaces, the experimental values of $E_{a}$ that lie between $7 / 12-9 / 12 E_{\text {coh }}(\mathrm{Zn})$ convey a poor interaction with the substrate that is partly improved upon hydroxylation $^{45}$ (open versus filled red circles, Figure 6). Significantly, in the presence of $\mathrm{Cr}$, $E_{a}$ values are of the order of $E_{c o h}(\mathrm{Zn})$ and well above those found on $\mathrm{Cr}$ free surfaces (blue symbols, Figure 6), which is assigned to strong $\mathrm{Zn}-\mathrm{Cr}$ bonds combined to neighboring $\mathrm{Zn}-\mathrm{Zn}$ interactions. ${ }^{44}$ Finally, while the $\mathrm{Zn}$ hardly sticks on oxidized $\mathrm{Cr}$, the sizeable values of $E_{a}$ (green symbols in Figure 6) reveal a strong interaction of $\mathrm{Zn}$ with defects at that surface.

\subsection{Plasmonics for real time analysis of $\mathrm{Zn}$ spreading on $\mathrm{Cr} / \mathrm{Al}_{2} \mathrm{O}_{3}(0001)$}

The study of the $\mathrm{Zn}$ adsorption on Crprecovered $\mathrm{Al}_{2} \mathrm{O}_{3}(0001)$ focuses on $\mathrm{Cr}$ film thicknesses of $0.3,0.43,0.7,2.3$ and $17.7 \AA$ (circled points in Figure 4) judged representative of the Cr effect. In final spectra (Figure 7),

\footnotetext{
aThe Redhead method (see Figure S7) based only on desorption peak position overestimates $E_{a}$ which, in a picture of quasi-equilibrium between adsorption and desorption, should not be greater than the bulk cohesive energy of zinc $E_{\text {coh }}(\mathrm{Zn})=1.35 \mathrm{eV} \cdot$ atom $^{-1}$ (Reference 101). Moreover, the desorption order is systematically found close to zero instead of $n=1$ assumed by Redhead analysis, ${ }^{75}$ if one excepts the thickest Cr layers for which $n \simeq 2$.
} 


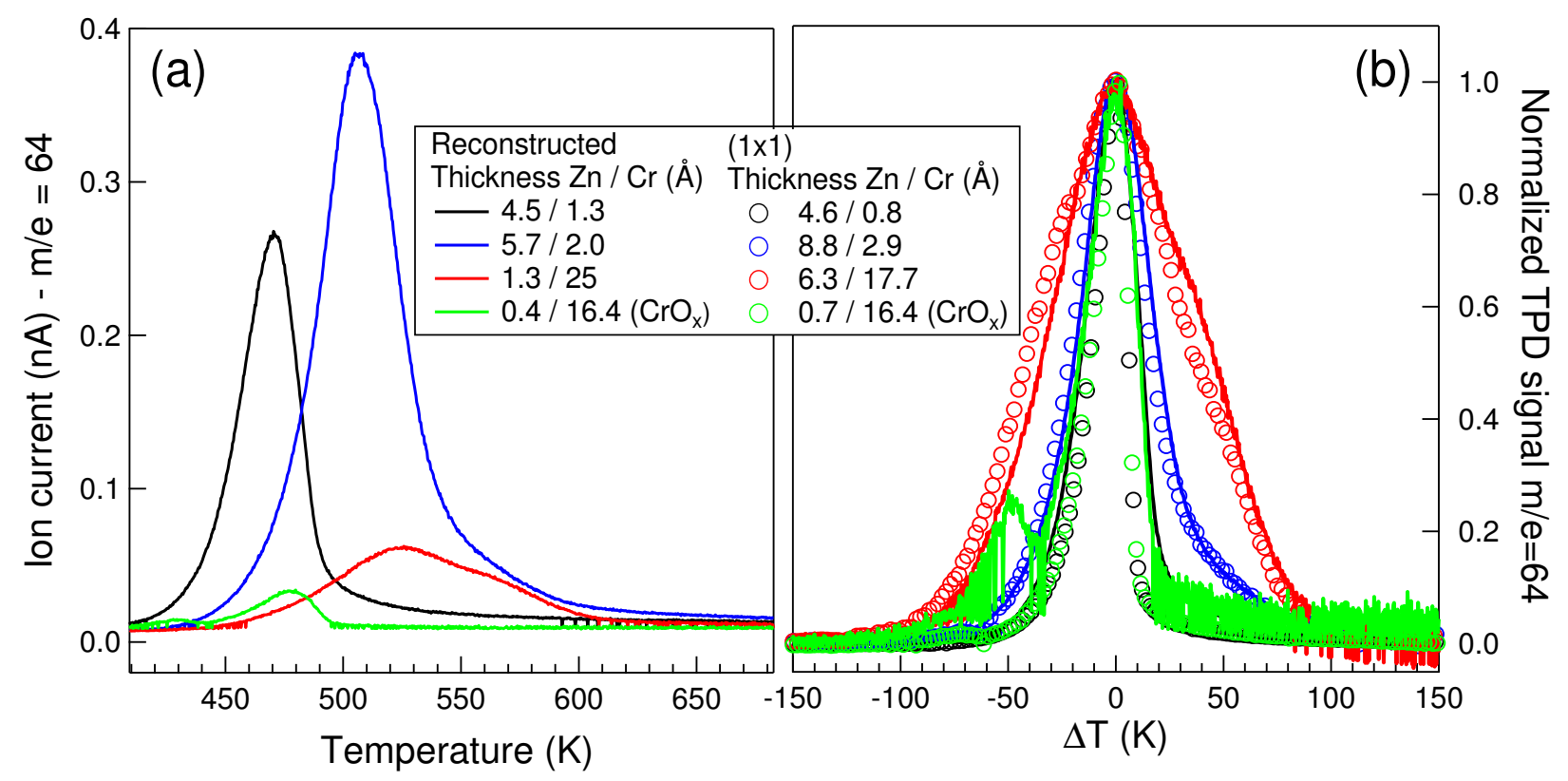

Figure 5: Desorption spectra of $\mathrm{Zn}(m / e=64)$ : (a) desorption spectra from reconstructed alumina (solid lines); (b) desorption peaks normalized to peak maximum and position for Cr-covered $(1 \times 1)$ (markers) and reconstructed alumina surfaces (solid lines). Film thicknesses are given in the figure. The heating rate is $\alpha=0.33 \mathrm{~K} . \mathrm{s}^{-1}$.
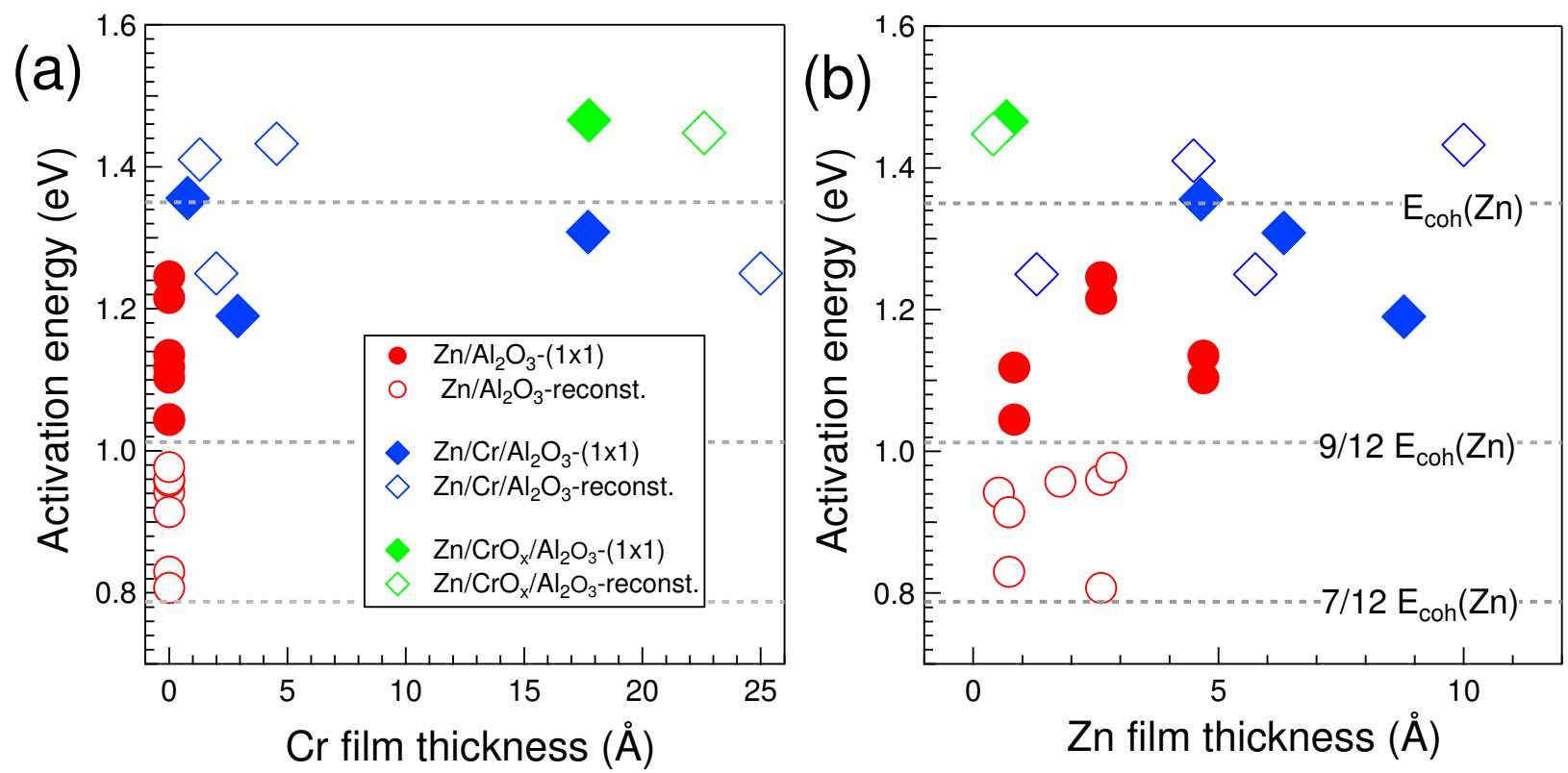

Figure 6: Zn desorption activation energies deduced from the leading edge analysis as a function of (a) $\mathrm{Cr}$ and (b) Zn film thickness for $(1 \times 1)$ (filled symbols) and reconstructed surfaces (open symbols). Data are compared to the bare surface case ${ }^{45,49}$ (red points) and the cohesive energy of Zn (dotted lines; see text). Despite the thermal contact between the insulating alumina and the heated back plate (estimated to $\Delta T \sim 50 \mathrm{~K}$ ), the uncertainties on the determined energies remain always well below fluctuations due the reproducibility of initial thicknesses and morphologies. 
the increase in intensity of the resonance corresponds to an increase in Zn condensed amount with $\mathrm{Cr}$ thickness. Notice that, beyond the amplitude, final SDRS line shapes are also impacted by the initial coverage in $\mathrm{Cr}$ (Figure 7-a). All spectra exhibit an asymmetric broad band typical for the plasmonic response of Zn nanoparticles ${ }^{45,57}$ that mainly consists in a parallel dipolar absorption mode excited on the $\mathrm{Zn}$ interband transitions. ${ }^{57}$

In Figure 7, the progressive shift of the SDRS resonance from 3.9 to $1.6 \mathrm{eV}$ as the $\mathrm{Cr}$ film thickens (and hence the $\mathrm{Zn}$ film) indicates a high sensitivity to $A_{r}$ and spreading of Zn particles. To overcome the discontinuity of the Cr layer which makes the dielectric simulation of the $\mathrm{Zn} / \mathrm{Cr} / \mathrm{Al}_{2} \mathrm{O}_{3}$ stack intractable, trends were derived from simulations of $\mathrm{Zn}$ /alumina (Figure 7-b). As supported by dipolar modeling, ${ }^{77}$ this simplification is all the more relevant as $\mathrm{Cr}$ deposits are thinner. $\mathrm{Zn}$ particles were modeled by truncated spheres and spheroids of increasing aspect ratios without accounting for particle-particle interaction and size/shape broadening (Section SII). The average thickness of $\mathrm{Zn}$ film (15 $\AA$ ) was kept constant in simulations. As compared to expectation for a continuous film (Figure 7 -b, red line), the energies of the broad bands observed in the ultra-violet/visible range point to a $3 \mathrm{D}$ growth mode; their progressive redshift demonstrates that $\mathrm{Zn}$ particles flatten upon increasing $\mathrm{Cr}$ thickness. Values of aspect ratio $A_{r}<2,2$ and $>8$ are assigned to $\operatorname{Zn}(0.6 \AA) / \operatorname{Cr}(0.3 \AA)$ (Figure 7; grey line), $\operatorname{Zn}(4.5 \AA) / \operatorname{Cr}(0.43 \AA)$ (Figure 7; green line), $\operatorname{Zn}(14.1 \AA) / \mathrm{Cr}(2.3 \AA)$ (Figure 7; light blue line) stacks, respectively. To highlight the promotion of $\mathrm{Zn}$ wetting by $\mathrm{Cr}$, comparisons are made with the Zn deposition on bare alumina at $100 \mathrm{~K}$ (Figure 7, black circles) and on the purposely oxidized $\mathrm{Cr}$ film (Figure 7-a, black squares). At $100 \mathrm{~K}, \mathrm{Zn}$ readily sticks ${ }^{45}$ but forms cluster of $A_{r} \sim 4$ indicative not only of a non-wetting behavior but also of a sizable spreading due of reduced mobility and out-of-equilibrium growth conditions, with an homologous temperature close to that of $\mathrm{Cr}$ at $300 \mathrm{~K}\left[T_{h}(\mathrm{Zn} ; 100 \mathrm{~K})=0.14\right.$;
$\left.T_{h}(\mathrm{Zn} ; 300 \mathrm{~K})=0.43 ; T_{h}(\mathrm{Cr} ; 300 \mathrm{~K})=0.14\right] . \mathrm{A}$ similar $A_{r}$ is observed for $\mathrm{Zn}$ deposited on the oxidized Cr film. Together with the low sticking of $\mathrm{Zn}$ (Figure 4), this demonstrates that $\mathrm{Cr}$ oxidation is detrimental to $\mathrm{Zn}$ wetting.

Now, to analyze the formation of $\mathrm{Zn}$ films, advantage was taken of the ability of SDRS for real-time analysis. Evolutions of SDRS spectra recorded all along $\mathrm{Zn}$ growth on $\mathrm{Cr} / \mathrm{Al}_{2} \mathrm{O}_{3}(0001)$ surfaces are compared in Figure 8. The integrated SDRS signal $\mathcal{A}_{s}$ defined by Equation 1 (Figure 9) provides, as in the case of the Cr growth (Section 3.1), a continuous representation of the evolution of $A_{r}$. The U-shape of $\mathcal{A}_{s}$ features a 3D growth regime $^{50}$ (except for the $\mathrm{Zn} / \mathrm{Cr}(17.7 \AA$ ) film). The first branch of the " $U$ " is assigned to a size-dependent equilibrium shape related to surface/interface stress effects ${ }^{50}$ at a about constant density of islands dictated by the predeposited Cr. The second branch of the "U" stems from coalescence. ${ }^{50}$ Among the cases selected, two very different behaviors can be distinguished, a steep increase in $\mathrm{Zn}$ sticking observed for minute amounts of pre-deposited Cr $(0.3,0.43$ and $0.7 \AA$ ) and then a slower change for Cr thickness of $2.3 \AA$ or higher (Figure 4 ), that are separately discussed in what follows.

\subsubsection{The seed layer}

On the $0.3 \AA$ Cr pre-deposited layer, which covers only a few percent of the surface (Figure 3b), Figure 7-a shows that there is about as much deposited $\mathrm{Zn}$ as on the oxidized $\mathrm{Cr}$ film, which means that $\mathrm{Cr}$ clusters capture zinc much more efficiently than the oxide in proportion to their relative surface. Since these $\mathrm{Cr}$ clusters are mostly oxidized, ${ }^{47,77}$ the sticking of $\mathrm{Zn}$ likely relates to the small proportion of metallic $\mathrm{Cr}$ they contain. The value of $A_{r} \sim 1.25$ derived from the position of the resonance (Figure 7) corresponds to a wetting angle $\theta_{e}\left(\mathrm{Zn} \mid \mathrm{Al}_{2} \mathrm{O}_{3}\right) \sim 127^{\circ}$ which is in fair agreement with the prediction of $125^{\circ}$ (adhesion energy of $0.23 \mathrm{~J} / \mathrm{m}^{2}$ and $\mathrm{Zn}$ surface energy of $0.54 \mathrm{~J} / \mathrm{m}^{2}$ ) for $\mathrm{Zn} /$ hydroxylated 

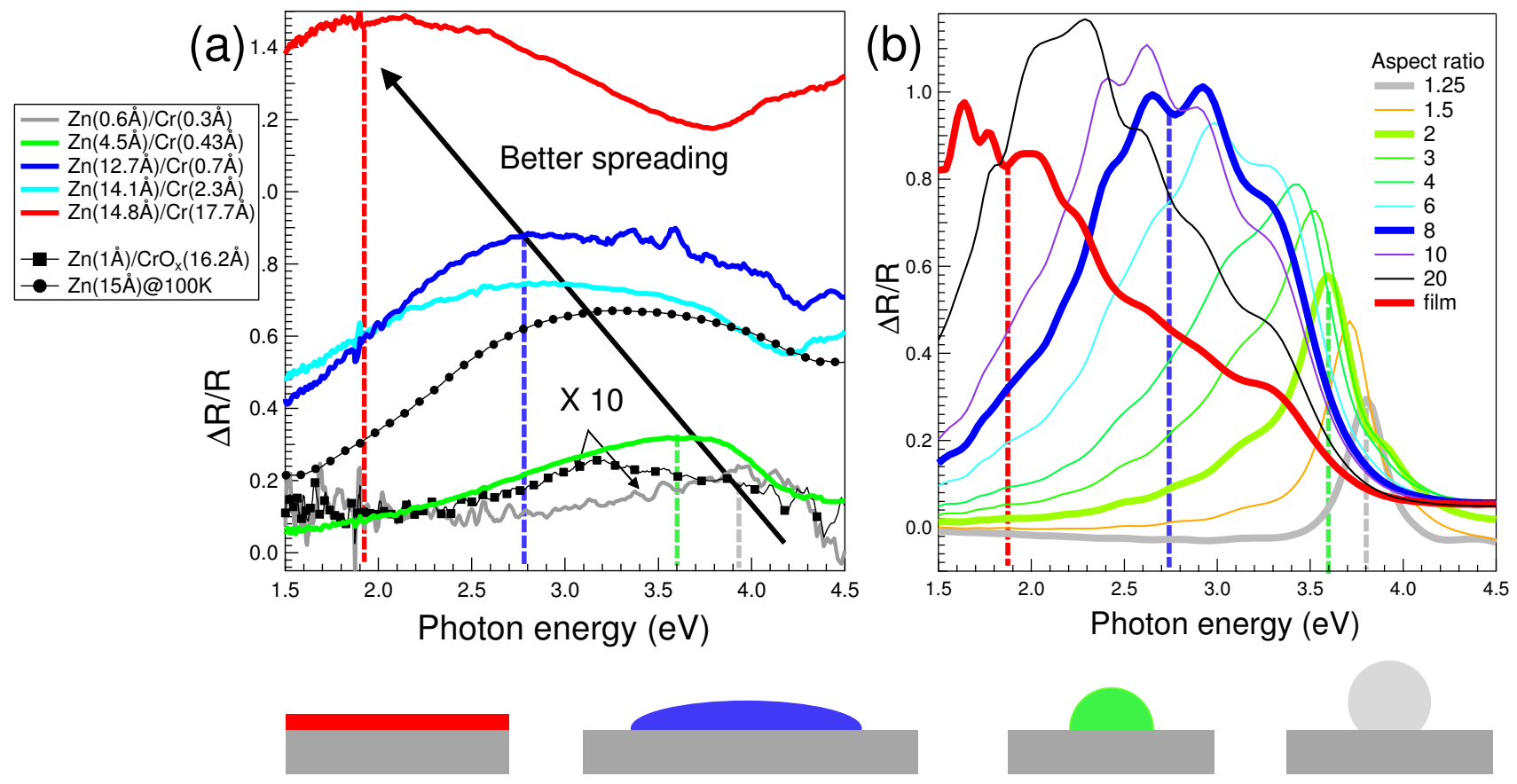

Figure 7: (a) Differential reflectivity spectra of $\mathrm{Zn} / \mathrm{Cr} / \mathrm{Al}_{2} \mathrm{O}_{3}(0001)$ in s-polarization recorded after the exposure of $\mathrm{Cr}$-precovered substrates to a constant nominal thickness of $\mathrm{Zn}(\sim 15 \AA)$. Actual condensed thicknesses as calibrated by photoemission are given in the figure. All spectra are referenced to the bare alumina spectrum. The comparison is made to spectra recorded during $\mathrm{Zn}$ growth on $\mathrm{Al}_{2} \mathrm{O}_{3}$ at $100 \mathrm{~K}$ (incident angle of $\theta_{0}=55^{\circ}$; Reference 45 ) and on an oxidized $\mathrm{Cr}$ film (black curves); (b) Simulated s-polarized spectra for $\mathrm{Zn} / \mathrm{Al}_{2} \mathrm{O}_{3}$ nanoparticles of different aspect ratios $A_{r}$. Truncated sphere shape is used for $A_{r}<2$ and oblate hemispheroid for $A_{r}>2$ (see schematics). In simulations of Figure b, the average film thickness is kept constant at $15 \AA$ and a comparison is made with the response of a continuous thin film of same thickness (red line). The position of the resonance (dotted vertical lines) allows to estimate particle aspect ratios. 
(a) $\mathrm{Zn}(0.6 \AA) / \mathrm{Cr}(0.3 \AA) / \mathrm{Al}_{2} \mathrm{O}_{3}$

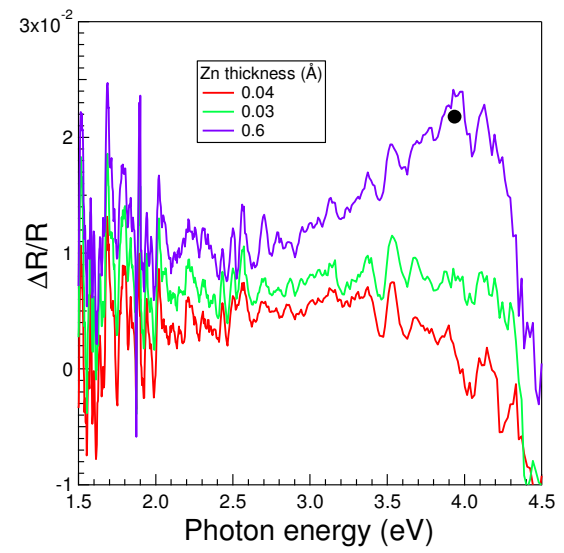

(d) $\mathrm{Zn}(14 \AA) / \mathrm{Cr}(2.3 \AA) / \mathrm{Al}_{2} \mathrm{O}_{3}$

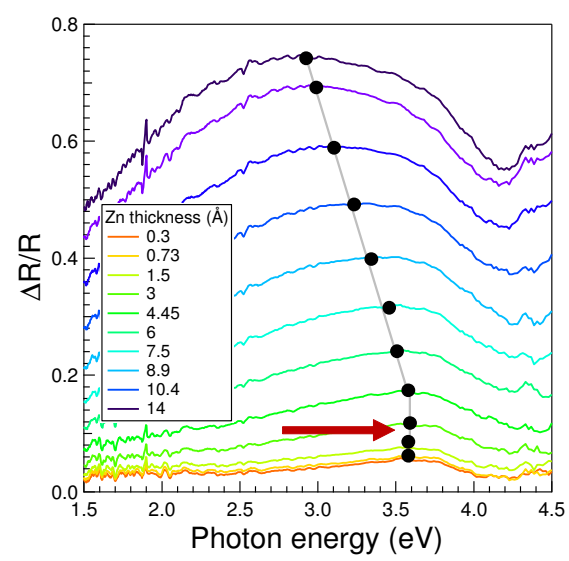

(b) $\mathrm{Zn}(4.5 \AA) / \mathrm{Cr}(0.43 \AA) / \mathrm{Al}_{2} \mathrm{O}_{3}$

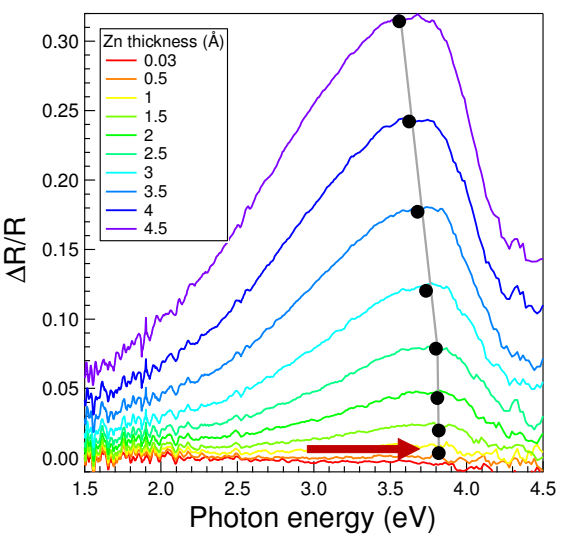

(c) $\mathrm{Zn}(12.7 \AA ̊ \AA) / \mathrm{Cr}(0.7 \AA) / \mathrm{Al}_{2} \mathrm{O}_{3}$

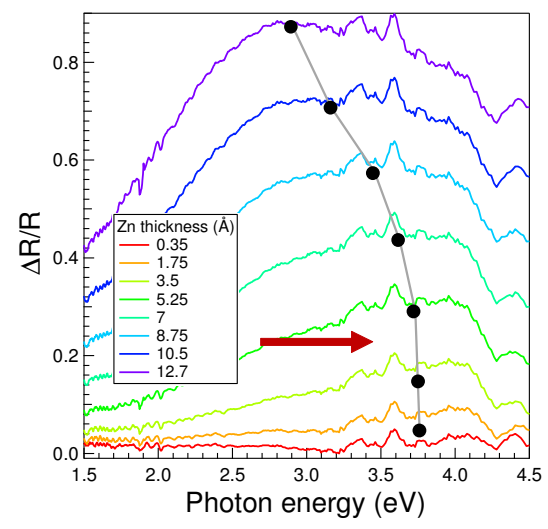

(e) $\mathrm{Zn}(14.8 \AA) / \mathrm{Cr}(17.7 \AA) / \mathrm{Al}_{2} \mathrm{O}_{3}$

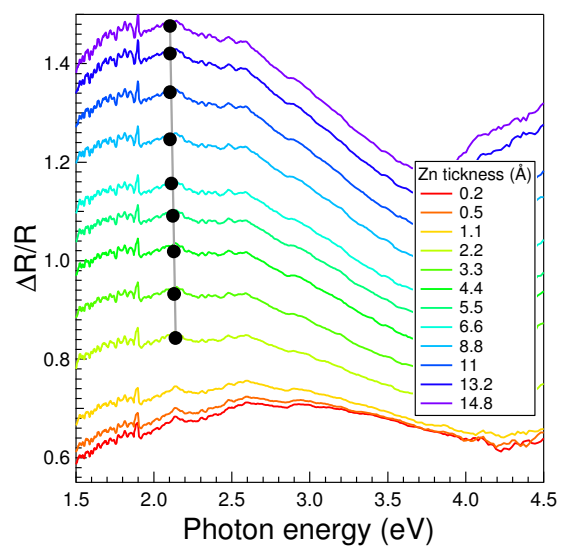

Figure 8: Evolution of the SDRS spectra (s-polarization) during the growth of Zn on Cr-precovered substrates. Spectra are normalized to the bare substrate reflectivity so that the first spectrum corresponds to that of the $\mathrm{Cr}$ deposit. The $\mathrm{Zn}$ film thicknesses indicated in the figure on each spectrum have been deduced by photoemission by assuming a constant sticking probability, i.e. deposited amounts that scale with time. Red arrows show the position of the minimum of the integrated SDRS signal $\mathcal{A}_{s}$ (Figure 9). 


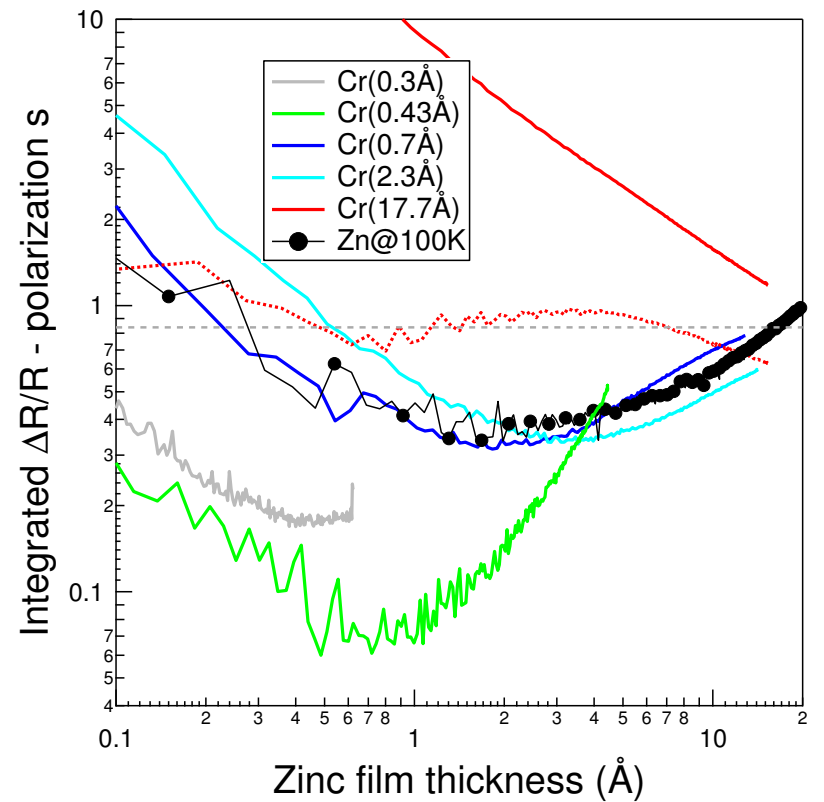

Figure 9: Evolution of the integrated SDRS signal $\mathcal{A}_{s}$ as a function of average $\mathrm{Zn}$ thickness on various $\mathrm{Cr}$-precovered substrates. The reddotted line corresponds to the $\mathrm{Cr}$ subtracted signal $\mathcal{A}_{s}^{Z n}$ of the $\operatorname{Zn}(14.8 \AA) / \operatorname{Cr}(17.7 \AA)$ deposit (see text for definition; Equation 4). It is compared to the theoretical expectation from the tabulated dielectric function of zinc (Equation 5; horizontal grey dotted line).
$\mathrm{Al}_{2} \mathrm{O}_{3}(0001) ;{ }^{46}$ on the contrary, it differs unambiguously from $\theta_{e}\left(\mathrm{Zn} \mid \mathrm{Al}_{2} \mathrm{O}_{3}\right)=78^{\circ}$ expected for $\mathrm{Zn} /$ dry Al-terminated alumina (adhesion energy $\left.0.65 \mathrm{~J} / \mathrm{m}^{2}\right) .{ }^{46}$ Therefore, $\mathrm{Zn}$ clusters can be seen as anchored to metallic $\mathrm{Cr}$ but in contact with the hydroxylated alumina surface which dictates the observed contact angle (aspect ratio) under the reasonable assumption that not all the surface $\mathrm{OH}$ have been reacted by the small deposited amount of Cr. Consistently, in Figure 9, the lack of second branch in the " $U$ " points to the absence of coalescence ${ }^{50}$ on a surface which only presents a minute coverage of metallic $\mathrm{Cr}$.

On the $0.43 \AA$ thick $\mathrm{Cr} /$ alumina film (Figure 8-b), the final Zn thickness amounts to $4.5 \AA$ accordingly to Figure 4 . The mild variation of the $\mathrm{Zn}$ resonance energy (Figure 8-b) from 3.8 to $3.65 \mathrm{eV}$ is associated to $A_{r}\left(\theta_{e}\left(\mathrm{Zn} \mid \mathrm{Al}_{2} \mathrm{O}_{3}\right)\right)$ ranging from 1.25 to $2\left(127\right.$ to $\left.100^{\circ}\right)$. As on the $0.3 \AA$ thick $\mathrm{Cr}$ film, Zn clusters can be viewed as anchored on widely dispersed small $\mathrm{Cr}$ islands although with a higher $\mathrm{Cr}$ metal/oxide ratio. At the onset of their growth, the contact angle $\theta_{e}\left(\mathrm{Zn} \mid \mathrm{Al}_{2} \mathrm{O}_{3}\right)=127^{\circ}$ shows that they are mainly in contact with a hydroxylated surface. Upon increasing $\mathrm{Zn}$ thickness, the increase in $A_{r}$ from 1.25 to 2 indicates a partial coalescence. The final $\mathrm{Zn}$ amount of $\sim 30 \%$ of the dose is far too strong to stem from a direct sticking of $\mathrm{Zn}$ on the $\mathrm{Cr}$ islands that cover less than $\sim 5 \%$ of the surface while $\mathrm{Zn}$ does not adsorb on the bare alumina. ${ }^{45,48}$ This suggests a residence time of physisorbed $\mathrm{Zn}$ long enough to allow a high probability of binding to existing $\mathrm{Cr}(\mathrm{Cr}-\mathrm{Zn})$ clusters or, in other words, a diffusion length of $\mathrm{Zn}$ adatoms of the order of the mean distance between the metallic spots of Cr. Figure 9 indicates that the aspect ratio of $\mathrm{Zn} / \mathrm{Cr}(0.43 \AA)$ particles remains rather low (low integrated $\mathcal{A}_{s}$ value) despite a flattening at the end of the growth process (second branch of the "U") which corresponds to a coalescence beyond the position of the minimum of the "U" as indicated by the red arrow (see also Figure 8-b).

Similar but more accentuated phenomena are observed on the $0.7 \AA$ thick $\mathrm{Cr}$ film (Fig- 
ure 8-c). The shift from 3.65 to $2.75 \mathrm{eV}$ of the resonance corresponds to $A_{r} \quad\left(\theta_{e}\left(\mathrm{Zn} \mid \mathrm{Al}_{2} \mathrm{O}_{3}\right)\right)$ ranging from 1.75 to $8\left(100\right.$ to $\left.30^{\circ}\right)$. With a initial wetting angle halfway between those related to hydroxylated $\left(125^{\circ}\right.$; Reference 45$)$ and bare $\left(78^{\circ}\right.$; Reference 46$)$ alumina, Zn clusters likely start to grow on a partially hydroxylated surface since higher the Cr coverage, lower the $\mathrm{OH}$ coverage. The higher density of metallic $\mathrm{Cr}$ seeds likely tends to flatten $\mathrm{Zn}$ particles. Consistently, the increase as a whole of the integrated intensity $\mathcal{A}_{s}$ (Figure 9 ) is indicative of such a flattening of $\mathrm{Zn}$ clusters with respect to observations made at lower Cr thickness. Then, the shift to higher $\mathrm{Zn}$ thickness of the minimum of $\mathcal{A}_{s}$ (Figure 9) means that a larger quantity of $\mathrm{Zn}$ is present at the onset of the coalescence (the second branch of the "U"). The final increase in $A_{r}$ of $\mathrm{Zn}$ clusters to higher values than observed at lower Cr thickness (Figure 9) evidences a more pronounced incomplete coalescence i.e. flatter objects. ${ }^{102,103}$ Therefore, at $300 \mathrm{~K}$, a partly oxidized $0.7 \AA$ thick $\mathrm{Cr}$ film, that covers only $\sim 5 \%$ of the alumina surface (Figure 3-b), allows the capture of more than $80 \%$ of a $\mathrm{Zn}$ dose. This rules out a sticking mechanism driven only by direct impact but rather supports the previous assumption of a long residence time on the alumina surface of the impinging $\mathrm{Zn}$ atoms with, in the present case, a diffusion length larger than the average distance between $\mathrm{Cr}$ islands.

Figure 10 sums up schematically the impact of the $\mathrm{Cr}$ clusters on Zn sticking and wetting in the above three cases. The metallic layer can be termed seed layer in that the few percents of metallic Cr promotes an almost complete $\mathrm{Zn}$ sticking on an alumina surface which does not otherwise bind this metal. The way $\mathrm{Zn}$ grows on pre-deposited $\mathrm{Cr}$ suggests an encapsulation of $\mathrm{Cr}$ by $\mathrm{Zn}$ while TPD points at a desorption energy above the cohesion energy of $\mathrm{Zn}$. Larger $\mathrm{Cr}$ surface energy compared to $\mathrm{Zn}$ (see above), sizable adhesion energy $^{46}\left(W(\mathrm{Cr} \mid \mathrm{Zn})=3.11 \mathrm{~J} / \mathrm{m}^{2}\right)$ and stronger $\mathrm{Zn}-\mathrm{Cr}$ than $\mathrm{Zn}-\mathrm{Zn}$ bonds (interface energy $\left.^{46} \gamma(\mathrm{Cr} \mid \mathrm{Zn})=-0.51 \mathrm{~J} / \mathrm{m}^{2}\right)$ explain both findings. In line with the hierar- chy of enthalpy of formation of their oxides $\left(\Delta H\left(\mathrm{Cr}_{2} \mathrm{O}_{3}\right)=-1134.7 \mathrm{~kJ} / \mathrm{mol} ; \Delta H(\mathrm{ZnO})=\right.$ $-350.46 \mathrm{~kJ} / \mathrm{mol}$ ) and first-principle atomistic calculations, ${ }^{42,44,45} \mathrm{Cr}$ forms stronger bonds than Zn with the alumina surface. Therefore, the enhancement of the spreading of $\mathrm{Zn}$ /alumina at $300 \mathrm{~K}$ does not stem from the wetting by $\mathrm{Cr}$, as poor as that of $\mathrm{Zn}$ on bare alumina at $100 \mathrm{~K}$, but from the strength of the bonding at the successive interfaces. Such seed layers are of interest in several respects: (i) they can be anticipated to mildly affect the intrinsic properties of the film whose sticking and spreading are favored; (ii) they offer a very flexible method of preparing a 3D particle distribution; (iii) most importantly, they are likely representative of realistic cases in which, due to environment, a pure continuous layer of an additive prone to oxidation can hardly be prepared.

\subsubsection{The adhesion layer}

Above $1.5 \AA$ (see Figure 3 ) Cr grows as high aspect ratio islands $\left(A_{r}(\mathrm{Cr}) \simeq 5\right)$ which cover progressively the surface before percolating around $10 \AA$. Consistently, Zn particles start flattening at the onset of deposition on $2.3 \AA$ of $\mathrm{Cr}$ and flatten even further as the buffer percolates (Figure 8-d). Incidentally, the "U" curve associated to $\mathrm{Zn}$ deposition at $100 \mathrm{~K}$ where kinetics plays a role shows a rather similar shape as those corresponding to 0.7 and $2.3 \AA$ of $\mathrm{Cr}$ (Figure 9).

On the percolated $14.8 \AA$ thick $\mathrm{Cr}$ film (Figure 8-e), estimates of $A_{r}(\mathrm{Zn}) \simeq 5 ; 8 ; 10$ for $\mathrm{Zn}$ thicknesses of $0.2,0.5$ and $1.1 \AA$ obtained by comparison to simulations (Figure 7b) indicates a good spreading. At $\mathrm{Zn}$ thicknesses larger than $2.2 \AA$, the nearly homothetic SDRS profile matches with a continuous morphology (red line in Figure 7 -b versus Figure 8-e). In fact, the spectrum of the $\mathrm{Zn}(14.8 \AA) / \mathrm{Cr}(17.7 \AA)$ film is nicely accounted for by a continuous film morphology as shown by the agreement with the dielectric simulations of a stack of $2 \mathrm{D}$ films whose thicknesses are 


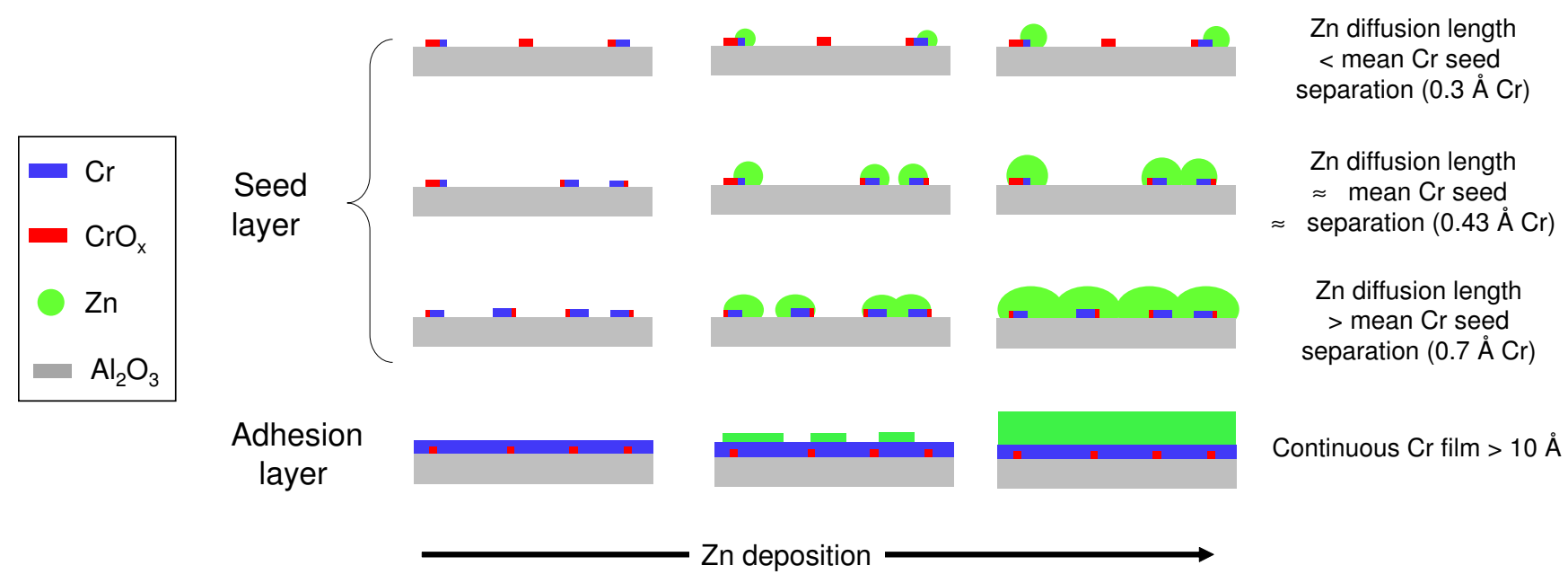

Figure 10: Schematic evolution of the Zn layer morphology as a function of Cr thickness (left: no $\mathrm{Zn}$; middle: intermediate $\mathrm{Zn}$ thickness; right: full Zn dose).

those given by the XPS measurements (see Figure S5). Finally, a continuous decrease of the corresponding integrated $\mathcal{A}_{s}$ is observed (Figure 9). In contrast to other samples, the spectra contain a strong initial Cr contribution (see first spectrum in Figure 8-e). Owing to the additivity of the first order surface susceptibilities for a stack of films, ${ }^{58,104}$ the $\mathrm{Cr}$ contribution can be subtracted as follows:

$$
\mathcal{A}_{s}^{Z n}\left(t_{Z n}\right)=\mathcal{A}_{s}\left(t_{Z n}\right)-\frac{t_{C r}}{t_{Z n}} \mathcal{A}_{s}^{C r}\left(t_{C r}\right),
$$

where $\mathcal{A}_{s}^{Z n}$ is the contribution of the $\mathrm{Zn}$ film alone, $\mathcal{A}_{s}^{C r}$ that of the $\mathrm{Cr}$ film before $\mathrm{Zn}$ growth and $t_{Z n}, t_{C r}$ the average thicknesses of the two films. The subtracted signal $\mathcal{A}_{s}^{Z n}\left(t_{Z n}\right)$ (Figure 9; red dotted line) does not follow the previous highlighted behavior for nanoparticles ${ }^{50}$ but is nearly constant as expected for the case of a thin continuous film. Indeed, for such a morphology, the integrated signal scales only with the imaginary part of the material dielectric constant ${ }^{50,57}$ (Figure S4-a):

$$
\mathcal{A}_{s}\left(t_{f}\right)=\int_{0}^{\infty} \operatorname{Im}\left[\epsilon_{Z n}(\omega)\right] d \omega .
$$

The experimental value is close to the integral of the tabulated $\mathrm{Zn}$ dielectric function, ${ }^{105}$ which appears as the limit value for all deposits. The nearly layer-by-layer growth mode suggested by the integrated signal is confirmed by the series of homothetic SDRS spectra observed above a Zn thickness of $2.2 \AA$ (Figure 8-e). Therefore, above $10 \AA$, percolated $\mathrm{Cr}$ films that nearly fully cover the alumina surface form what can be called perfect adhesion layers for $\mathrm{Zn}$ (see Figure 10).

\section{Conclusion}

A detailed analysis of the chemical state, sticking and spreading/wetting of $\mathrm{Zn}$ on $\mathrm{Cr}$ predeposited film on $\alpha-\mathrm{Al}_{2} \mathrm{O}_{3}(0001)$ at $300 \mathrm{~K}$ has been performed by a combination of surface sensitive techniques involving surface differential reflectivity spectroscopy. Beyond its ability to analyze the morphology of very small supported clusters, the technique has demonstrated its flexibility in monitoring the growth of multimetallic films. At the onset of the $\mathrm{Cr}$ deposition, the oxidation of $\mathrm{Cr}$ by reaction with the surface $\mathrm{OH}$ is very detrimental for $\mathrm{Zn}$ sticking. Being nil on the bare alumina surface, the sticking coefficient of metallic Zn shows two very distinct behaviors, which do not scale at all with the metallic $\mathrm{Cr}$ coverage:

- at very low coverages, metallic chromium acts as a seed layer which captures $\mathrm{Zn}$ atoms that diffuse over the surface, leading to a steep increase of the Zn sticking and a Zn spreading that far exceeds the 
Cr coverage. Zn clusters are anchored on the $\mathrm{Cr}$ seeds that they encapsulate, but their wetting behavior is dictated by the contact with alumina. As an example, the pre-deposition of $0.7 \AA$ of $\mathrm{Cr}$ covering $\sim 5 \%$ of the alumina surface allows the capture of $\sim 80 \%$ of a $\mathrm{Zn}$ dose of $15 \AA$.

- at increasing film thicknesses, $\mathrm{Cr}$ forms high aspect ratio islands that cover progressively the surface before percolating around $10 \AA$. At this point, the $\mathrm{Cr}$ film behaves as an adhesion layer. In the limit of the optical measurements, Zn growth mode is found to be 2D; Zn perfectly wets the Cr-covered alumina surface.

The ability of tiny amounts of metal to dramatically enhance the sticking of a film is of great practical interest. Firstly, it shows that under realistic conditions in which the growth of a full metallic buffer adlayer cannot be achieved, a non-continuous and partially oxidized layer can induce sufficient sticking. In a very different perspective, the anchoring of a layer by discrete seeds can keep the properties of the film intact, which is often desired. Finally, such anchoring offers a method for preparing a 3D particle distribution. The mechanisms highlighted herein are quite general since, as metals used in buffers do no wet large band gap oxides, their efficiency relies on the strength of the buffer-substrate and filmbuffer bonds.

Acknowledgement We are grateful to Jacek Goniakowski (INSP) for fruitful discussions on the energetics of metallic particles. This work was supported by French state funds managed by the ANR within the Investissements d'Avenir programme under reference ANR-11IDEX-0004-02, and more specifically within the framework of the Cluster of Excellence MATISSE led by Sorbonne Universités.

\section{Supporting Information Avail- able}

The Supporting Information is available free of charge at XXX

SI : Photoemission quantification; SII: Surface Differential Reflectivity Spectroscopy; SIII: Temperature Programmed Desorption.

\section{References}

(1) Barmak, K., Coffey, K., Eds. Metallic films for electronic, optical and magnetic applications; WP Woodhead Publishing, 2014.

(2) Campbell, C. T.; Parker, S. C.; Starr, D. E. The effect of size-dependent nanoparticle energetics on catalyst sintering. Science 2002, 298, 811.

(3) Fu, Q.; Wagner, T. Interaction of nanostructured metal overlayers with oxide surfaces. Surf. Sci. Rep. 2007, 62, 431498.

(4) Evans, A. G.; Hutchinson, J. W.; Wei, Y. Interface adhesion: effects of plasticity and segregation. Acta Mater. 1999, 47, 4093-4113.

(5) Abadias, G.; Chason, E.; Keckes, J.; Sebastiani, M.; Thompson, G. B.; Barthel, E.; Doll, G. L.; Murray, C. E.; Stoessel, C. H.; Martinu, L. Review Article: Stress in thin films and coatings: Current status, challenges, and prospects. J. Vac. Sci. Technol., A 2018, 36, 020801.

(6) Thompson, C. V. Solid-state dewetting of thin films. Annu. Rev. Mater. Res. 2012, 42, 399-434.

(7) Jacquet, P.; Podor, R.; Ravaux, J.; Teisseire, J.; Gozhyk, I.; Jupille, J.; Lazzari, R. Grain growth: the key to understand solid-state dewetting of silver thin films. Scr. Mater. 2016, 115, 128 - 132. 
(8) Jacquet, P.; Podor, R.; Ravaux, J.; Lautru, J.; Teisseire, J.; Gozhyk, I.; Jupille, J.; Lazzari, R. On the solid-state dewetting of polycrystalline thin films: capillary versus grain growth approach. Acta Mater. 2018, 143, 281 - 290.

(9) Henriquez, R.; Roco, R.; Bravo, S.; Del Campo, V.; Gonzalez-Fuentes, C.; Donoso, S.; Häberle, P. Effect of a metallic surfactant on the electrical percolation of gold films. Appl. Surf. Sci. 2019, 489, 403-408.

(10) Kästle, G.; Boyen, H. G.; Koslowski, B.; Plettl, A.; Weigl, F.; Ziemann, P. Growth of thin, flat, epitaxial (111) oriented gold films on c-cut sapphire. Surf. Sci. 2002, 498, 168-74.

(11) Chen, W.; Chen, K. P.; Thoreson, M. D.; Kildishev, A. V.; Shalaev, V. M. Ultrathin, ultrasmooth, and low-loss silver films via wetting and annealing. Appl. Phys. Lett. 2010, 97, 211107.

(12) J., L. V.; Kobayashi, N. P.; Islam, M. S.; Wu, W.; Chaturvedi, P.; Fang, N. X.; Wang, S. Y.; Williams, R. S. Ultrasmooth silver thin films deposited with a germanium nucleation layer. Nano Letters 2009, 9, 178-182.

(13) Formica, N.; Ghosh, D. S.; Carrilero, A.; Chen, T. L.; Simpson, R. E.; Pruneri, V. Ultrastable and atomically smooth ultrathin silver films grown on a copper seed layer. ACS Applied Materials \& Interfaces 2013, 5, 3048-3053.

(14) Zhang, J.; Fryauf, D. M.; Garrett, M.; Logeeswaran, V.; Sawabe, A.; Islam, M. S.; Kobayashi, N. P. Phenomenological model of the growth of ultrasmooth silver thin films deposited with a germanium nucleation layer. Langmuir 2015, 31, 7852-7859.

(15) Zhao, G.; Wang, W.; Bae, T.-S.; Lee, S.G.; Mun, C.; Lee, S.; Yu, H.; Lee, G.-H.;
Song, M.; Yun, J. Stable ultrathin partially oxidized copper film electrode for highly efficient flexible solar cells. Nat. Commun. 2015, 6, 8830.

(16) Fukuda, K.; Lim, S. H. M.; Anders, A. Coalescence of magnetron-sputtered silver islands affected by transition metal seeding (Ni, Cr, Nb, Zr, Mo, W, Ta) and other parameters. Thin Solid Films 2008, 516, 4546-4552.

(17) Aouani, H.; Wenger, J.; Gérard, D.; Rigneault, H.; Devaux, E.; Ebbesen, T. W.; Mahdavi, F.; Xu, T.; Blair, S. Crucial role of the adhesion layer on the plasmonic fluorescence enhancement. ACS Nano 2009, 3, 2043-2048.

(18) Siegfried, T.; Ekinci, Y.; Martin, O. J. F.; Sigg, H. Engineering metal adhesion layers that do not deteriorate plasmon resonances. ACS Nano 2013, 7, 2751-2757.

(19) Todeschini, M.; Bastos da Silva Fanta, A.; Jensen, F.; Wagner, J. B.; Han, A. Influence of $\mathrm{Ti}$ and $\mathrm{Cr}$ adhesion layers on ultrathin Au films. ACS Appl Mater Interfaces 2017, 9, 37374-37385.

(20) Romanyuk, A.; Steiner, R.; Mathys, D.; Thommen, V.; Oelhafen, P. Use of tin as a surfactant material for the growth of thin silver films on silicon oxide. Surf. Sci. 2008, 602, L49 - L52.

(21) Søndergård, E.; Kerjan, O.; Abriou, D.; Jupille, J. Growth and buffer effects of titanium on silver $/ \alpha-\mathrm{Al}_{2} \mathrm{O}_{3}(0001)$. Eur. Phys. J. D 2003, 24, 343-345.

(22) Lazzari, R.; Jupille, J. Interfacial chemistry and wetting of metallic films on the hydroxylated $\alpha-\mathrm{Al}_{2} \mathrm{O}_{3}(0001)$ surface. Phys. Rev. B 2005, 71, 045409.

(23) Liu, H.; Wang, B.; Leong, E. S. P.; Yang, P.; Zong, Y.; Si, G.; Teng, J.; Maier, S. A. Enhanced surface plasmon resonance on a smooth silver film with a 
seed growth layer. ACS Nano 2010, 4, 3139-3146.

(24) Dehm, G.; Scheu, C.; Rühle, M.; Raj, R. Growth and structure of internal $\mathrm{Cu} / \mathrm{Al}_{2} \mathrm{O}_{3}$ and $\mathrm{Cu} / \mathrm{Ti} / \mathrm{Al}_{2} \mathrm{O}_{3}$ interfaces. Acta. Mater. 1998, 46, 759-771.

(25) Chatain, D.; Coudurier, L.; Eustathopoulos, N. Wetting and interfacial bonding in ionocovalent oxide-liquid metal systems. Revue Phys. Appl. 1988, 23, $1055-1064$.

(26) Yoshitake, M.; Yagyu, S.; Chikyow, T. Novel method for the prediction of an interface bonding species at alumina/metal interfaces. J. Vac. Sci. Technol., A 2014, 32, 021102.

(27) Hemmingson, S. L.; Campbell, C. T. Trends in adhesion energies of metal nanoparticles on oxide surfaces: Understanding support effects in catalysis and nanotechnology. ACS Nano 2017, 11, 1196-1203.

(28) Bauer, E. Phaenomenologische Theorie der Kristallabscheidung an Oberflaechen I. Z. Kristallogr 1958, 110, 372-394.

(29) Chatain, D.; Rivollet, I.; Eustathopoulos, N. Adhésion thermodynamique dans les systèmes non-réactifs métal liquidealumine. J. Chim. Phys. 1986, 83, 561567.

(30) Campbell, C. T. Ultrathin metal films and particles on oxide surfaces: structural, electronic and chemisorptive properties. Surf. Sci. Rep. 1997, 27, 1-111.

(31) Markov, I.; Kaischew, R. Influence of supersaturation on the mode of crystallization on crystalline substrates. Thin Solid Films 1976, 32, 163-167.

(32) Lüth, H. Surface and Interfaces of Solids; Springer Study Edition; Springer-Verlag Berlin Heidelberg, 1992.
(33) Lazzari, R.; Jupille, J. Growth kinetics and size-dependent wetting of $\mathrm{Ag} / \alpha$ $\mathrm{Al}_{2} \mathrm{O}_{3}(0001)$ nanoparticles studied via the plasmonic response. Nanotechnology 2012, 23, 135707.

(34) Lazzari, R.; Goniakowski, J.; Cabailh, G.; Cavallotti, R.; Trcera, N.; Jupille, J.; Lagarde, P. Surface and epitaxial stress for supported metal clusters. Nano Lett. 2016, 16, 2574-2579.

(35) Lazzari, R.; Simonsen, I.; Bedeaux, D.; Vlieger, J.; Jupille, J. Polarizability of truncated spheroidal island supported by a substrate : models and applications. Eur. Phys. J. B 2001, 24, 267-284.

(36) Chambers, S.; Droubay, T.; Jennison, D.; Mattsson, T. Laminar growth of ultrathin metal films on metal oxides: Co on hydroxylated $\alpha-\mathrm{Al}_{2} \mathrm{O}_{3}(0001)$. Science 2002, 297, 827-831.

(37) Dai, Z.; Borghetti, P.; Chenot, S.; David, P.; Jupille, J.; Cabailh, G.; Goniakowski, J.; Lazzari, R. Aluminium segregation profiles in the (110), (100) and (111) surface regions of the $\mathrm{Fe}_{0.85} \mathrm{Al}_{0.15}$ random body-centered cubic alloy. Appl. Surf. Sci. 2019, 492, 886-895.

(38) Dai, Z.; Alyabyeva, N.; Borghetti, P.; Chenot, S.; David, P.; Koltsov, A.; Renaud, G.; Jupille, J.; Cabailh, G.; Lazzari, R. Al-rich $\mathrm{Fe}_{0.85} \mathrm{Al}_{0.15}(100)$, (110) and (111) surface structures. Appl. Surf. Sci. 2020, 509, 145312.

(39) Dai, Z.; Alyabyeva, N.; Van den Bossche, M.; Borghetti, P.; Chenot, S.; David, P.; Koltsov, A.; Renaud, G.; Jupille, J.; Cabailh, G. et al. Oxide at the Al-rich $\mathrm{Fe}_{0.85} \mathrm{Al}_{0.15}(110)$ surface. Phys. Rev. Materials 2020, 4, 074409.

(40) Guttmann, M. Diffusive phase transformations in hot dip galvanizing. Reactive phase formation at interfaces and diffusion processes. 1994; pp 527-548. 
(41) Drillet, P.; Zermout, Z.; Bouleau, D.; Mataigne, J.; Claessens, S. Selective oxidation of high $\mathrm{Si}, \mathrm{Mn}$ and $\mathrm{Al}$ steel grades during recrystallization annealing and steel/Zn reactivity. La Revue de Métallurgie-CIT 2004, 101, 831-837.

(42) Cavallotti, R.; Goniakowski, J.; Lazzari, R.; Jupille, J.; Koltsov, A.; Loison, D. Role of surface hydroxyl groups on zinc adsorption characteristics on $\alpha-\mathrm{Al}_{2} \mathrm{O}_{3}(0001)$ surfaces: first-principles study. J. Phys. Chem. C 2014, 118, 13578-13589.

(43) Cavallotti, R.; Thi Le, H.-L.; Goniakowski, J.; Lazzari, R.; Jupille, J.; Koltsov, A.; Loison, D. New routes for engineering the adhesion at $\mathrm{Zn} / \alpha-\mathrm{Al}_{2} \mathrm{O}_{3}(0001)$ interface. Phys. Chem. Chem. Phys. 2016, 18, 30323039 .

(44) Le, H.-A. T.; Goniakowski, J.; Noguera, C.; Koltsov, A.; Mataigne, J.M. First-principles study on the effect of pure and oxidized transition-metal buffers on adhesion at the alumina/zinc interface. J. Phys. Chem. C 2016, 120, 9836-9844.

(45) Thi Le, H.-L.; Lazzari, R.; Goniakowski, J.; Cavallotti, R.; Chenot, S.; Noguera, C.; Jupille, J.; Koltsov, A.; Mataigne, J.-M. Tuning adhesion at metal/oxide interfaces by surface hydroxylation. J. Phys. Chem. C 2017, 121, 11464-11471.

(46) Le, H.-L. T.; Goniakowski, J.; Noguera, C.; Koltsov, A.; Mataigne, J.M. Improving adhesion at the alumina/zinc interface by stainless steel buffers. J. Phys. Chem. C 2017, 121, 25143-25151.

(47) Messaykeh, M.; Goniakowski, J.; Cabailh, G.; Jupille, J.; Lazzari, R.; Lagarde, P.; Trcera, N. Chromium adsorption reveals a persistent hydroxylation of vacuum-annealed $\alpha-\mathrm{Al}_{2} \mathrm{O}_{3}(0001) . J$. Phys. Chem. C 2019, 123, 29245-29254.

(48) Rodriguez, J. A.; Kuhn, M.; Hrbek, J. Interaction of silver, cesium, and zinc with alumina surfaces: thermal desorption and photoemission studies. J. Phys. Chem. 1996, 100, 18240-18248.

(49) Cavallotti, R. Effets de la terminaison de l' $\alpha$-alumine sur le comportement au mouillage du zinc. Ph.D. thesis, Pierre and Marie Curie University, France, 2014 .

(50) Lazzari, R.; Jupille, J.; Cavallotti, R.; Chernysheva, E.; Castilla, S.; Messaykeh, M.; Hérault, Q.; Meriggio, E. Plasmonics of supported nanoparticles reveals adhesion at the nanoscale: implications for metals on dielectrics. ACS Applied Nano Materials 2020, 3, 1215712168.

(51) http://www.physik.de/mateck,.

(52) Campbell, C.; Valone, S. Design consideration for simple gas dosers in surface science application. J. Vac. Sci. Technol. A 1985, 3, 408-411.

(53) Renaud, G.; Villette, B.; Vilfan, I.; Bourret, A. Atomic structure of the $\alpha-\mathrm{Al}_{2} \mathrm{O}_{3}(0001)(\sqrt{31} \times \sqrt{31}) R \pm 9^{\circ}$ reconstruction. Phys. Rev. Lett. 1994, 73, 1825-1828.

(54) Guénard, P.; Renaud, G.; Barbier, A.; Gautier-Soyer, M. Determination of the $\alpha-\mathrm{Al}_{2} \mathrm{O}_{3}(0001)$ surface relaxation and termination by measurements of crystal truncation rods. Surf. Rev. Lett. 1998, 5,321 .

(55) Renaud, G. Oxide surfaces and metal/oxide interfaces studied by Grazing Incidence X-Ray Scattering. Surf. Sci. Rep. 1998, 32, 1-90.

(56) Kaplan, W. D.; Mxillejans, H.; Rühle, M.; Rödel, J.; Claussen, N. N. $\mathrm{Ca}$ segregation to basal surfaces in 
$\alpha$-alumina. J. Am. Ceram. Soc. 1995, 78, 2841-2844.

(57) Lazzari, R.; Jupille, J.; Cavallotti, R.; Simonsen, I. Model-free unraveling of supported nanoparticles plasmon resonance modes. J. Phys. Chem. C 2014, 118, 7032-7048.

(58) Bedeaux, D.; Vlieger, J. Optical Properties of Surfaces; Imperial College Press: London, 2001.

(59) Lazzari, R.; Simonsen, I.; Jupille, J. Interfacial susceptibilities in nanoplasmonics via inversion of Fresnel coefficients. Plasmonics 2014, 9, 261-272.

(60) Lazzari, R.; Renaud, G.; Revenant, C.; Jupille, J.; Borenstzein, Y. Adhesion of growing nanoparticles at a glance: Surface differential reflectivity spectroscopy and grazing incidence small angle $\mathrm{X}$ ray scattering. Phys. Rev. B 2009, 79, 125428 .

(61) Simonsen, I.; Lazzari, R.; Jupille, J.; Roux, S. Numerical modelling of the optical response of supported metallic particles. Phys. Rev. B 2000, 61, 7722-7733.

(62) Lazzari, R.; Simonsen, I. GranFilm: a software for calculating thin-layer dielectric properties and Fresnel coefficients. Thin Solid Films 2002, 419, 124-136.

(63) Lazzari, R.; Roux, S.; Simonsen, I.; Jupille, J.; Bedeaux, D.; Vlieger, J. Multipolar optical absorptions in supported metallic particles: the case of Ag/ $\mathrm{Al}_{2} \mathrm{O}_{3}(0001)$. Phys. Rev. B 2002, 65, 235424-1.

(64) Lazzari, R.; Jupille, J. Quantitative analysis of nanoparticle growth through plasmonics. Nanotechnology 2011, 22, 445703.

(65) GranFilm can be downloaded with a user guide from: http://www.insp.jussieu.fr/Logiciels-.html.
(66) Yeh, J.; Lindau, I. Atomic subshell photoionization cross sections and assymetry parameters: $1 \leq Z \leq$ 300. At. Data Nucl. Data Tables 1985, 32, 1-155.

(67) Tougaard, S. Universality classes of inelastic electron scattering cross-sections. Surf. Interface Anal. 1997, 25, 137-154.

(68) Jablonski, A. Evaluation of procedures for overlayer thickness determination from XPS intensities. Surf. Sci. 2019, $688,14-24$.

(69) Jablonski, A.; Powell, C. J. The electron attenuation length revisited. Surf. Sci. Rep. 2002, 47, 33-91.

(70) Jablonski, A.; Powell, C. J. Improved algorithm for calculating transport cross sections of electrons with energies from $50 \mathrm{eV}$ to $30 \mathrm{keV}$. Phys. Rev. B 2007, 76, 085123.

(71) Jablonski, A. Photoelectron transport in the surface region of solids: universal analytical formalism for quantitative applications of electron spectroscopies. $J$. Phys. D: Appl. Phys. 2015, 48, 075301.

(72) Tanuma, S.; Powell, C. J.; Penn, D. R. Calculation of electron inelastic mean free paths (IMFPs) VII. Reliability of the TPP-2M IMFP predictive equation. Surf. Interface Anal. 2003, 35, 268-275.

(73) Lazzari, R. Igor Pro Paris Photoemission Package can be downloaded with a user guide from: http://www.insp.upmc.fr/I4P-Igor-ProParis-Photoemission.html?lang $=\mathrm{en}$.

(74) Ibach, H. Physics of Surfaces and Interfaces; Springer-Verlag Berlin Heidelberg, 2006; Vol. 10.

(75) Redhead, P. A. Thermal desorption of gases. Vacuum 1962, 12, 203-211.

(76) De Jong, A. M.; Niemantsverdriet, J. W. Themal desorption analysis: comparative test of ten commonly applied procedures. Surf. Sci. 1990, 233, 355-365. 
(77) Messaykeh, M. A fundamental approach of the wetting at $\mathrm{Zn} / \mathrm{Cr} / \mathrm{Al}_{2} \mathrm{O}_{3}$ interface: the effect of a $\mathrm{Cr}$ buffer. Ph.D. thesis, Sorbonne University, France, 2018.

(78) Palik, E. D. Handbook of Optical Constants of Solids; Academic Press, 1985; Vol. 1-3.

(79) Sterrer, M.; Freund, H. J. Towards realistic surface science models of heterogeneous catalysts: influence of support hydroxylation and catalyst preparation method. Catal. Lett. 2013, 143, 375-385.

(80) Libuda, J.; Frank, M.; Sandell, A.; Andersson, S.; Brühwiler, P. A.; Baümer, M.; Mårtenson, N.; Freund, H. J. Interaction of rhodium with hydroxylated model substrates. Surf. Sci. 1997, 384, 106-119.

(81) Niu, C.; Shepherd, K.; Martini, D.; Tong, J.; Kelber, J.; Jennison, D. R.; Bogicevic, A. $\mathrm{Cu}$ interactions with $\alpha$ $\mathrm{Al}_{2} \mathrm{O}_{3}$ (0001): effects of surface hydroxyl groups versus dehydroxylation by Ar-ion sputtering. Surf. Sci 2000, 465, 163-176.

(82) Kelber, A.; Niu, C.; Shepherd, K.; Jennison, D. R.; Bogicevic, A. Copper wetting of $\alpha-\mathrm{Al}_{2} \mathrm{O}_{3}(0001)$ : theory and experiment. Surf. Sci. 2000, 446, 76-88.

(83) Lazzari, R.; Jupille, J. Chemical reaction via hydroxyl groups at the $\mathrm{Ti} / \alpha-\mathrm{Al}_{2} \mathrm{O}_{3}$ interface. Surf. Sci. 2002, 507-510, 683687.

(84) Baima, J.; Le, H. L. T.; Goniakowski, J.; Noguera, C.; Koltsov, A.; Mataigne, J.M. Theoretical study of metal/silica interfaces: $\mathrm{Ti}, \mathrm{Fe}, \mathrm{Cr}$ and $\mathrm{Ni}$ on betacristobalite. Phys. Chem. Chem. Phys 2020, 2, 21453-21462.

(85) Vapor pressure calculator: https://www.iap.tuwien.ac.at/.

(86) Anders, A. A structure zone diagram including plasma-based deposition and ion etching. Thin Solid Films 2010, 518, 4087-4090.
(87) Depla, D.; Braeckman, B. R. Quantitative correlation between intrinsic stress and microstructure of thin films. Thin Solid Films 2016, 604, 90 - 93.

(88) NIST X-ray photoelectron spectroscopy database. https://srdata.nist.gov/xps/Default.aspx.

(89) Ley, L.; Kowalczyk, S. P.; McFeely, F. R.; Pollak, R. A.; Shirley, D. A. X-ray photoemission from zinc: evidence for extraatomic relaxation via semilocalized excitons. Phys. Rev. B 1973, 8, 2392-2402.

(90) Kowalczyk, S. P.; Pollak, R. A.; McFeely, F. R.; Ley, L.; Shirley, D. A. $L_{2,3} M_{45} M_{45}$ Auger spectra of metallic copper and zinc: theory and experiment. Phys. Rev. B 1973, 8, 2387-2391.

(91) Schön, G. Auger and direct electron spectra in X-ray photoelectron studies of zinc, zinc oxide, gallium and gallium oxide. J. Electron Spectrosc. Relat. Phenom. 1973, 2, 75-86.

(92) Antonides, E.; Janse, E. C.; Sawatzky, G. A. LMM Auger spectra of $\mathrm{Cu}, \mathrm{Zn}, \mathrm{Ga}$, and Ge, II. Relationship with the $\mathrm{L}_{23}$ photoelectron spectra via the $\mathrm{L}_{2} \mathrm{~L}_{3} \mathrm{M}_{45}$ Coster-Kronig process. Phys. Rev. B 1977, 15, 4596.

(93) Antonides, E.; Janse, E. C.; Sawatzky, G. A. LMM Auger spectra of $\mathrm{Cu}, \mathrm{Zn}, \mathrm{Ga}$, and Ge. I. Transition probabilities, term splittings, and effective Coulomb interaction. Phys. Rev. B 1977, 15, 1669.

(94) Fox, J. H.; Nuttall, J. D.; Gallon, T. E. Solid state effects in the Auger spectrum of zinc and oxidized zinc. Surf. Sci. 1977, 63, 390-402.

(95) Kourouklis, H.; Nix, R. The uptake and characterisation of zinc on low index silver and copper surfaces. Surf. Sci. 1994, $314,201-211$. 
(96) Rodriguez, J. A.; Kuhn, M. Interaction of zinc with transition-metal surfaces: electronic and chemical perturbations induced by bimetallic bonding. J. Phys. Chem. 1996, 100, 381-389.

(97) Rodriguez, J. A. Physical and chemical properties of bimetallic surfaces. Surf. Sci. Rep. 1996, 24, $223-287$.

(98) Jeroro, E.; Lebarbier, V.; Datye, A.; Wang, Y.; Vohs, J. M. Interaction of CO with surface PdZn alloys. Surf. Sci. 2007, 601, 5546 - 5554 .

(99) Ho, C. S.; Martono, E.; Banerjee, S.; Roszell, J.; Vohs, J.; Koel, B. E. Alloy formation and chemisorption at $\mathrm{Zn} / \mathrm{Pt}(111)$ bimetallic surfaces using alkali : ISS, XPD, and TPD. J. Phys. Chem. A 2013, 117, 11684-11694.

(100) Wagner, T.; Fu, Q.; Winde, C.; Tsukimoto, S.; Phillipp, F. A comparative study of the growth of $\mathrm{Cr}$ on (110) $\mathrm{TiO}_{2}$ rutile, (0001) $\alpha-\mathrm{Al}_{2} \mathrm{O}_{3}$ and (100) $\mathrm{SrTiO}_{3}$ surfaces. Interface Sci. 2004, 12, 117126.

(101) http://www.webelements.com.

(102) Jeffers, G.; Dubson, M. A.; Duxbury, P. M. Island to percolation transition during growth of metal films. J. Appl. Phys. 1994, 75, 5016-5020.

(103) Zhao, G.; Jeong, E.; Choi, E. A.; $\mathrm{Yu}$, S. M.; Bae, J.-S.; Lee, A.-G.; Han, S. Z.; Lee, G. H.; Yun, J. Strategy for improving Ag wetting on oxides: Coalescence dynamics versus nucleation density. Appl. Surf. Sci. 2020, 510, 145515.

(104) Haarmans, M.; Bedeaux, D. Optical properties of thin films up to second order in the thickness. Thin Solid Films 1995, 258, 213-223.

(105) Nash, D. J.; Sambles, J. R. Surface plasmon-polariton study of the optical dielectric function of zinc. J. Mod. Opt. 1998, 45, 2585-2596. 


\section{For Table of Contents Use Only}

Title: An In Situ and Real Time Plasmonic Approach of Seed/Adhesion Layers: Chromium Buffer Effect at the Zinc/Alumina Interface

Authors: Maya Messaykeh, Stéphane Chenot, Pascal David, Gregory Cabailh, Jacques Jupille, Alexey Koltsov, Rémi Lazzari

\section{TOC Graphic}

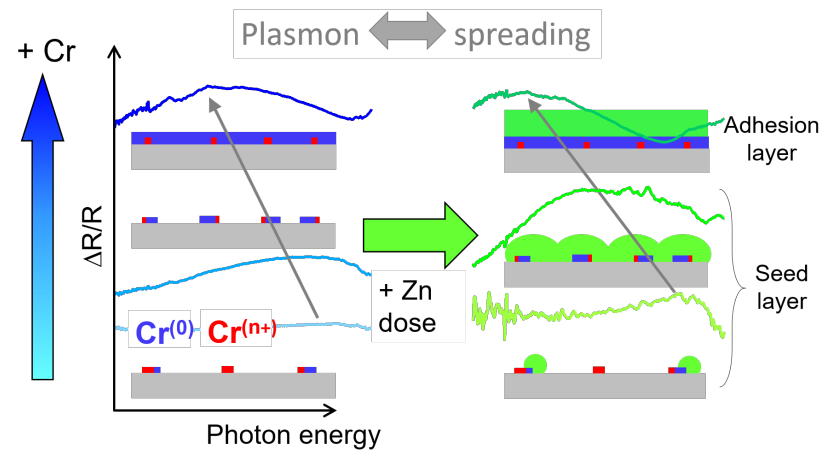

Outline of $\mathrm{Cr}$ buffer effect on $\mathrm{Zn} / \mathrm{Al}_{2} \mathrm{O}_{3}$ growth as derived from plasmonics. 